\title{
Custos de Transporte e Urbanização: Evidências a partir da Criação de Cidades*
}

\author{
Flávia Chein ${ }^{\dagger}$, Juliano J. Assunção ${ }^{\ddagger}$, Mauro Borges Lemos ${ }^{\S}$
}

\author{
Contents: 1. Introdução; 2. Estratégia Empírica; 3. Base de Dados; 4. Resultados; \\ 5. Considerações Finais; A. Tabelas. \\ Keywords: Urbanização; Custos de Transporte; Rodovias; Criação de Cidades. \\ JEL Code: R11; 015; 018.
}

Este artigo investiga a relação entre urbanização e rendimentos individuais em cidades emergentes (pouco urbanizadas), a partir da relação entre custo de transporte e urbanização. Para tanto, considera as cidades criadas a partir da construção da rodovia Belém-Teresina e da pavimentação da rodovia Cuiabá-Porto Velho. Os resultados mostram que existe uma relação positiva entre urbanização e rendimento em cidades de pequeno porte, mas essa relação não é, necessariamente, direta. Características individuais e a estrutura produtiva e do mercado de trabalho local aparecem como importantes canais dessa relação. Ao contrário do que ocorre em cidades médias e grandes, o acúmulo de capital humano nos pequenos aglomerados urbanos não parece ter efeito sobre os rendimentos individuais. This paper investigates the relationship between urbanization and individual incomes by exploring the role of transport costs in the process of urbanization. Our empirical framework is built on the importance of the transport networks, especially roads, in creating urban agglomerations and new towns. We find that, although this relationship exists, it is not, necessarily, direct. Productive structure and local labor market are important channels that link urbanization and individual income in emerging towns around the roads. There is no statistically significant relationship between the accumulation of human capital in those towns and the individual incomes differently from the findings for large and medium-sized cities.

\section{INTRODUÇÃO}

Residir no meio urbano está associado a maiores rendimentos individuais? Residir em um município onde uma maior proporção de pessoas vivem no meio urbano significa ganhos mais elevados? Se existe

\footnotetext{
*Este trabalho foi realizado com o apoio financeiro da FAPEMIG e CNPq, por meio da concessão de bolsa de Pós-Doutorado Júnior a Flávia Chein, nos anos de 2007 e 2008 respectivamente.

${ }^{\dagger}$ CEDEPLAR/UFMG. E-mail: f chein@cedeplar .ufmg.br

¥Departamento de Economia, PUC-Rio. E-mail: juliano@econ.puc-rio.br

$\S$ CEDEPLAR/UFMG. E-mail: mbl@cedeplar.ufmg.br
} 
relação entre urbanização e desenvolvimento, quais os canais que explicam tal relação? No meio urbano as remunerações são melhores pela maior diversificação e produtividade do trabalho, pelas amenidades locais e facilidades de infra-estrutura, dada a existência de provedores públicos? Ou, simplesmente, é a aglomeração de pessoas, capital humano, e maior interação social fruto do ambiente urbano que explicam os maiores rendimentos individuais?

Buscar respostas para tais questões, recorrentes na literatura tanto de economia regional como de economia urbana, não é tarefa fácil. O entendimento do fenômeno da urbanização, ou de forma mais geral, da formação de aglomerações urbanas, e sua relação com o crescimento tem sido bastante explorado teórica e empiricamente (Lewis (1954); Hoselitz (1953); Christaller (1966); Lösh (1954); Pred (1966); Jacobs (1969); Henderson (1974); Glaeser et al. (1992); Glaeser et al. (1995); Glaeser (1999); Fujita and Thisse (2002); Fujita et al. (1999); Black and Henderson (1999), entre outros). Tanto a literatura de desenvolvimento como a de economia regional e urbana reconhece que urbanização e renda são positivamente correlacionadas (Kuznets (1966); Jacobs (1969); Bairoch (1988); Glaeser and Mare (2001); Acemoglu et al. (2002) e Berry and Glaeser (2005)).

O deslocamento da população do campo para a cidade é propiciado por mudanças estruturais que, juntamente com os incrementos populacionais, geram ganhos de produtividade por trabalhador e aumento da renda per capita associados ao crescimento econômico (Kuznets, 1966). Desse modo, à medida que são gerados excedentes na agricultura e desenvolvidos sistemas de transporte, possibilitando a utilização do excedente no comércio, torna-se possível o aparecimento dos chamados centros urbanos (Bairoch, 1988).

Empiricamente, a partir desse referencial teórico, Acemoglu et al. (2002) mostram a relação entre urbanização e renda por meio de regressões do logaritmo natural da renda per capita em função da taxa de urbanização. Os resultados encontrados apontam que, em 1995, um país com uma taxa de urbanização 10 pontos percentuais superior tinha, em média, uma renda per capita $43 \%$ mais elevada. Os autores fazem, ainda, um exercício empírico, a partir de dados históricos, considerando um painel para diferentes países no período de 1750 a 1913, incluindo dummies de países e período. Nesse caso, um país com taxa de urbanização 10 pontos percentuais mais elevada, tinha, em média, uma renda per capita $30 \%$ maior.

Dada esta forte correlação entre urbanização e renda, vários teóricos da economia urbana têm se dedicado a investigar, teórica e empiricamente, os ganhos salariais de se residir em uma área urbana, densamente povoada. Glaeser and Mare (2001) encontram um prêmio salarial médio de $24,9 \%$, controlando para características individuais, para aqueles que residem em áreas densamente povoadas. Quando incluem efeitos fixos para cada indivíduo, como forma de controlar para características não observáveis que podem estar correlacionadas com o status de residência no meio urbano, as estimativas de prêmio salarial nas grandes cidades ficam em torno de 10,9 e 4,5\%, dependendo da base de dados utilizada.

Diante desses resultados e do fato de ainda serem poucos os trabalhos que tratam a urbanização não apenas sob o ponto de vista da mudança do setor agrícola para o setor industrial, mas consideram, de fato, a existência de cidades, como em Henderson and Wang (2005), este artigo explora, exatamente, o fenômeno da urbanização que ocorre via criação de novas cidades. O foco de análise, diferentemente do que ocorre na maior parte dos trabalhos empíricos, como em Glaeser et al. (1992), são cidades em estágios iniciais de urbanização, com média de população abaixo de 15 mil habitantes, onde ainda prevalece uma grande concentração de ocupados no setor primário, baixa escolaridade, elevado percentual da população abaixo de 15 anos e com acesso limitado a alguns serviços urbanos, como telefonia e rede geral de abastecimento. A existência de tais cidades é comum em países em desenvolvimento, cuja fronteira de recursos naturais induz a incorporação econômica de novos territórios (Fafchamps and Shilpi, 2005). Tal realidade, na qual se insere o caso brasileiro, é a motivação principal para investigação dos mecanismos pelos quais se dá a relação entre urbanização e renda em cidades de pequeno porte.

Dessa forma, diferentemente de outros trabalhos empíricos (Da Mata et al. (2005a,b, 2006)), trabalhamos o conceito de cidade e, consequentemente de urbanização, a partir das definições do Instituto 
Brasileiro de Geografia e Estatística (IBGE). Como o nosso objetivo não é estudar as aglomerações urbanas e sim os pequenos aglomerados populacionais ou cidades emergentes, o conceito de município do IBGE é válido, a despeito de suas eventuais limitações. Tais aglomerados estão associados a um tipo de urbanização embrionária a partir do momento que a implantação de uma sede de município gera uma demanda por serviços básicos de infra-estrutura urbana, como acesso a rede geral de água e esgoto, telefonia, energia elétrica, entre outros, além de gerar uma diversificação de atividades, com desenvolvimento de um setor de comércio e serviços, ainda que em estágio bastante inicial.

Para identificar municípios de urbanização recente, a estratégia adotada baseia-se na relação existente entre custo de transporte e urbanização. Firmas e trabalhadores tendem a se aglomerar objetivando reduzir custos, obter melhores salários e, de forma mais geral, ter acesso a mercados diversificados.

Empiricamente, essa relação é tratada pela ligação entre eixos viários e existência de aglomerados urbanos, ou sedes municipais. A hipótese é de que ao se conectar duas localidades, em que pelo menos uma delas tenha iniciado o processo de transformação de uma economia rural para uma economia urbana, várias localidades ao longo e ao redor da rodovia tornam-se mais atrativas, dada a sua maior proximidade a outros mercados regionais e nacionais. Fluxos migratórios chegam a essas regiões em busca de melhores oportunidades gerando um aumento da população. Criam-se novas aglomerações que acabam por dar origem a outras cidades.

Construímos, dessa forma, um exercício empírico com base em duas obras de infra-estrutura rodoviária localizadas na Amazônia: a construção da Belém-Teresina (1976) e a pavimentação da Cuiabá-Porto Velho (1983/1984). Os resultados da análise exploratória evidenciam a criação de várias cidades ao longo de uma área de cerca de $200 \mathrm{~km}$ ao redor da rodovia após a realização dessas obras, que atuam, de certo modo, como um choque de urbanização. No entorno da Belém-Teresina, foram criados 126 novos municípios após a construção da rodovia, sendo que, destes, 34 têm sua sede atravessada pela rodovia. Já na área da Cuiabá-Porto Velho, foram implantadas 76 novas sedes de município, atravessadas pela rodovia, de 1980 a 2000. Aparece aí, então, uma rara oportunidade de se tratar a relação entre urbanização e renda em municípios de formação recente, mediante uma análise de equilíbrio parcial, construída a partir de estimações de equações de rendimentos individuais.

$\mathrm{Na}$ análise para as duas rodovias, encontramos uma correlação positiva entre urbanização e rendimento. Para os municípios novos da área de análise da Belém-Teresina, a correlação significativa é entre a taxa de urbanização e o rendimento individual, enquanto que, nos municípios novos da Cuiabá-Porto Velho, o que afeta o rendimento individual é o fato do indivíduo residir ou não no meio urbano. Contudo, essas correlações se enfraquecem quando condicionamos em variáveis demográficas, de estrutura produtiva, educação e infra-estrutura básica.

Os resultados indicam que a maior parte da correlação positiva entre urbanização e rendimento está mesmo associada a diferenças nas características individuais, do trabalho e de estrutura produtiva entre o meio urbano e o rural e o município mais ou menos urbanizado.

De outro lado, em nenhuma das áreas analisadas, é encontrada uma correlação entre indicadores municipais de educação e o rendimento individual.

Além dessa parte introdutória, o artigo é estruturado da seguinte forma: a Seção 2 descreve o exercício empírico baseado na relação entre custo de transporte e urbanização; na Seção 3 é apresentada a base de dados; a Seção 4 apresenta e discute os resultados e, finalmente, na Seção 5 são tecidas as considerações finais. 


\section{ESTRATÉGIA EMPÍRICA}

\subsection{Custos de transporte e urbanização: Evidências empíricas}

Esta subseção destaca, especialmente, o papel dos custos de transporte no aumento da urbanização via desmembramento de municípios e criação de novas sedes, a partir de referenciais teóricos e evidências do caso brasileiro.

Toda a história da economia regional foi construída em cima da existência de custos de transporte como mecanismo de formação das aglomerações econômicas. As decisões econômicas são criadas e limitadas pelos custos de se transportar bens e mercadorias de um lugar para outro. (Christaller (1966); Lösh (1954); Isard and Bramhall (1960); Fujita et al. (1999); Glaeser and Kohlhase (2003)).

Trabalhos empíricos têm apontado uma estreita relação entre o acesso ao litoral, o percentual de população vivendo em áreas costeiras, urbanização e crescimento econômico (Gallup et al., 1998). 0 desenvolvimento em áreas do interior dos países depende, em última instância, de investimentos em infra-estrutura, ainda que sejam regiões com abundância de recursos naturais (Henderson, 1999).

Historicamente, tomando o exemplo americano, no século XVIII, quando os custos de transporte eram muito elevados, e os bens transportados basicamente por água, a estrutura e localização das cidades refletiam esses altos custos de transporte. Como as rodovias e ferrovias eram caras e raras, toda grande cidade estava localizada ao longo de cursos d'água, como Boston, Chicago, New York, New Orleans, entre outras. As cidades pequenas estavam no interior do país e eram especializadas na provisão de serviços básicos para aqueles que viviam da produção para o auto-consumo (Glaeser and Kohlhase, 2003).

O papel dos custos de transporte no processo de desenvolvimento brasileiro se assemelha à experiência americana. Grande parte dos municípios mais antigos está instalada ao longo do litoral e em leitos de rios, enquanto que o surgimento mais recente de cidades no interior acompanha a implantação da malha rodoviária nacional.

Vários estudos, entre os quais destacam-se os de Diniz (1987), Castro $(1984,1988,2002)$ e Castro et al. (1999) enfatizam a estreita relação entre desenvolvimento da infra-estrutura de transporte e crescimento econômico regional. Especial ênfase tem sido dada ao papel da pavimentação e expansão da malha rodoviária nacional para o aumento da produtividade agrícola. No caso da expansão agrícola do cerrado brasileiro, a infra-estrutura de transportes tem se mostrado de fundamental importância para o escoamento da produção e ganhos de produtividade no cultivo de grãos, notadamente, na chamada nova fronteira agrícola impulsionada pelas plantações de soja no Centro-Oeste (Castro, 2002).

A Figura 1, onde aparecem em destaque a Região Norte e o Estado do Maranhão, evidencia que as sedes de municípios mais antigas, na Amazônia, apresentam-se nas proximidades da malha hidroviária. Em Roraima (RR), por exemplo, as sedes dos dois municípios mais antigos estão às margens da hidrovia de ligação com o Amazonas e os poucos municípios criados mais recentemente acompanham a malha rodoviária. No próprio Estado do Amazonas (AM), as cidades foram sendo constituídas seguindo, exatamente, os cursos d'água navegáveis.

Com a implantação na década de 70 de ligações rodoviárias objetivando aproximar essas regiões menos desenvolvidas do restante do país, aparecem novas aglomerações urbanas ao longo dos eixos rodoviários, como fica evidente quando olhamos o Estado de Rondônia (RO).

Na região Norte, por ser uma região de florestas densas, são as estradas que abrem caminho e formam clareiras em torno das quais torna-se possível o surgimento de novos povoados. Caminhando no sentido oeste-leste no mapa, no Estado do Pará (PA) vimos que os municípios mais antigos estão mais próximos ao litoral, como é o caso da capital Belém, ou, a exemplo do que ocorre nos outros Estados da região, sobre as hidrovias.

De outro lado, quando se analisa a aglomeração de cidades em Estados de ocupação mais antiga, como o Maranhão (MA), fica evidenciado que o processo de urbanização se inicia no litoral e caminha em direção ao interior acompanhando as rodovias construídas há mais tempo. o conjunto de pontos 
pretos que se inicia no litoral maranhense e segue na direção sudeste, são sedes de municípios que acompanham a BR-135, que liga São Luís (MA) ao sul do Piauí, implantada ainda na década de 1960. Nos Estados da região Nordeste, a exemplo do que ocorre na região Centro-sul, não se pode desprezar, também, o papel das ferrovias, precursoras das rodovias como principal meio de transporte de passageiros e mercadorias.

Por fim, quando se olha o Estado do Tocantins (TO), criado a partir da Constituição de 1988, fica claro que a existência de uma malha rodoviária mais densa possibilita a formação de uma pluralidade de sedes municipais, especialmente no sentido norte-sul.

Figure 1: Malha Rodoviária e Hidroviária - Região Norte e Estado do Maranhão

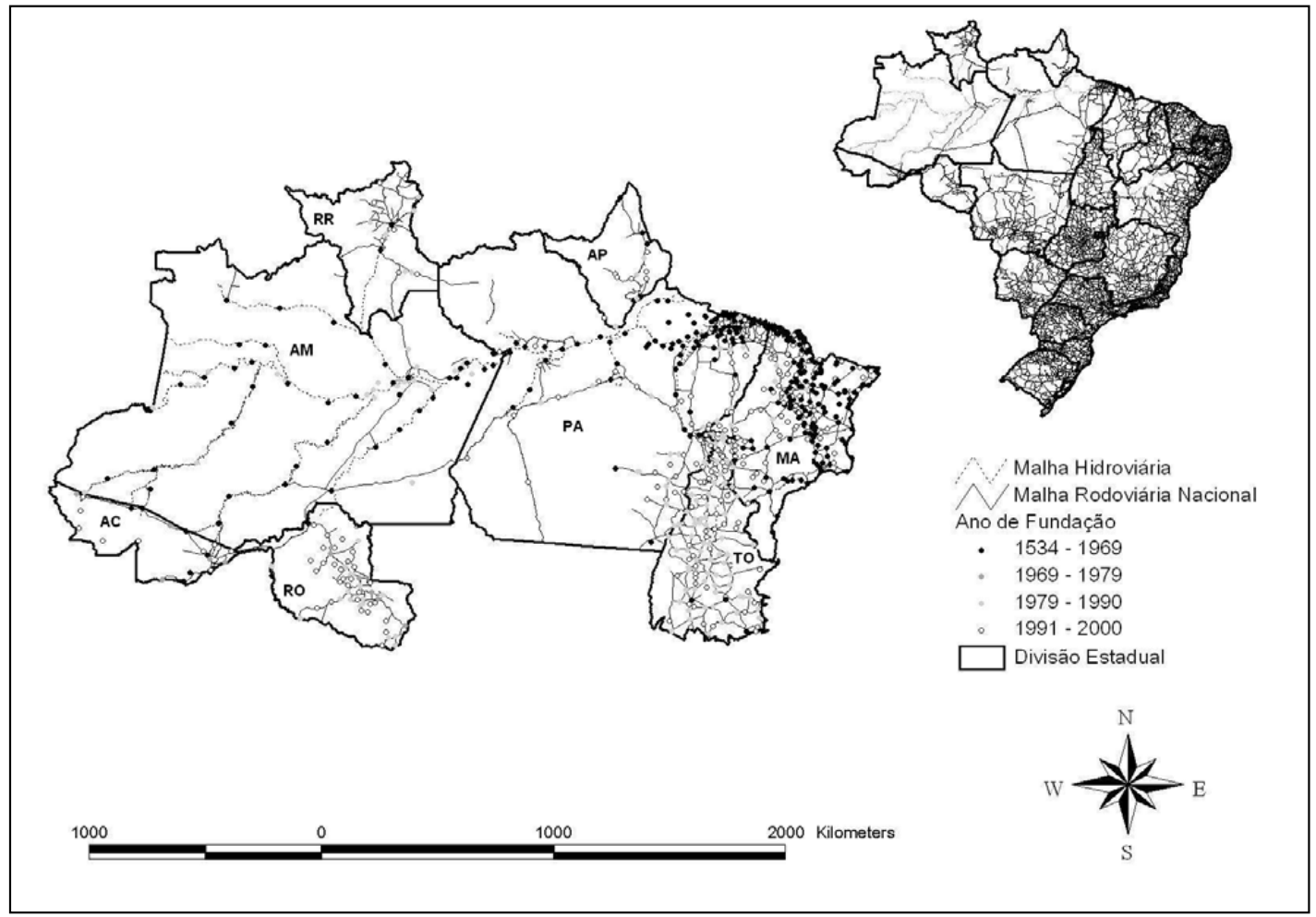

: A Figura apresenta as malhas rodoviárias (linhas cheias) e hidroviária (linhas tracejadas) implantadas que atravessam as Unidades da Federação da Amazônica Legal, e as sedes de município existentes em 2000. Os pontos cheios em preto são as sedes mais antigas, os pontos brancos, com contorno preto apenas, são os municípios criados entre 1991 e 2000. Fonte: Elaboração própria, com base nas malhas municipal e rodoviária nacional e informações do ano de fundação dos municípios (Banco de dados INGEO/Ministério do Planejamento, 2002).

As duas obras rodoviárias que vamos examinar nesse trabalho passam pela região Amazônica, a pavimentação da Cuiabá-Porto Velho (BR-364) e a implantação da Belém-Teresina (BR-316), e têm como objetivo a integração da região com o restante do país. A escolha de tais rodovias objetiva mitigar eventuais limitações na identificação do exercício, que supõe reduções relevantes no custo de transporte e indubitáveis aumentos de acessibilidade de localidades do entorno aos mercados regionais e nacional. 
Embora as regiões atravessadas pelas duas rodovias façam parte da Amazônia, uma à leste e outra à oeste, suas características e estágios de ocupação eram bastante diferentes no momento das obras de construção e pavimentação, o que permite comparar as consequências da melhoria de infra-estrutura rodoviária e os eventuais efeitos sobre urbanização em contextos distintos.

A Belém-Teresina foi entregue ao tráfego totalmente pavimentada, o que torna a rodovia mais perene. Por outro lado, a ligação entre estas capitais não estava diretamente associada aos projetos de assentamentos do Governo Federal, já que os objetivos com a sua construção eram bem menos ambiciosos do que aquele da Transamazônica, por exemplo, que era vista, no momento de sua construção, como o eixo de desenvolvimento e integração da Amazônia, ao longo do qual se consolidaria uma economia baseada em projetos agropecuários com fortes incentivos governamentais. A construção da Belém-Teresina era vista, simplesmente, como uma entre muitas obras necessárias para a integração territorial através da consolidação da malha rodoviária do país.

Essa rodovia, formada por trechos da BR-316 e da BR-010 (entroncamento com a Belém-Brasília), constitui um importante elo entre as regiões Norte e Nordeste do País. Foi construída e entregue ao tráfego em 1976, com $1.087 \mathrm{~km}$ pavimentados (Sant’Anna, 1998). À época de sua construção, formava, junto com a Belém-Brasília, a porta de entrada da porção leste do território nacional para a Amazônia, pois concluía o acesso, por terra, entre as áreas próximas ao litoral do Nordeste e a malha hidroviária do Norte.

Já a pavimentação da Cuiabá-Porto Velho (formada por um trecho da BR-364) transforma um acesso precário e inundado em parte do ano em uma ligação com condições perenes de trafegabilidade, representando uma maior proximidade da parte sudoeste da fronteira de ocupação da Amazônia Ocidental com os mercados do sul e sudeste, em um momento em que os investimentos do Governo Federal já eram escassos e a política de colonização já havia sido redirecionada.

A rodovia Cuiabá-Porto Velho possui, hoje, $1.090 \mathrm{~km}$ pavimentados, ligando Porto Velho (RO) a Cuiabá (MT) e a Rio Branco (AC), cortando o Estado de Rondônia de sudeste a noroeste e atravessando boa parte do Estado de Mato Grosso (Rondônia-SEPLAG, 2002). Entretanto, a análise a ser enfocada no presente artigo tem como referência a pavimentação do principal trecho da rodovia, que vai de Porto Velho a Cuiabá, entregue ao tráfego a partir 1983, estando concluída em setembro de 1984. O objetivo principal da pavimentação ocorrida nos anos 80 era organizar a ocupação da região e prover a infraestrutura necessária para o aproveitamento do potencial agrícola local. (Fearnside (1987); Bank (1999); Margulis (1991)).

\subsection{Evidências para construção do exercício empírico}

A definição da área de análise das rodovias foi feita a partir da interseção entre o trecho da malha rodoviária nacional e a malha municipal, construída a partir da compatibilização dos municípios existentes em 1970 e 2000 (Chein et al., 2007). Foram definidos como municípios ${ }^{1}$ pertencentes à área de análise da rodovia aqueles cuja menor distância entre a coordenada da sede existente em 1970 e a rodovia não ultrapassasse $200 \mathrm{~km}$. A opção pelo critério de distância em detrimento do critério de vizinhança baseado em contigüidade, ou fronteira geográfica comum, apóia-se no fato de existir uma grande heterogeneidade entre o tamanho dos municípios, o que se deve não só há uma diferença natural de suas áreas territoriais, mas também ao resultado da compatibilização das malhas municipais.

Em seguida, tais municípios foram divididos em quatro grupos, segundo sua posição em relação às rodovias, ou seja:

i) os municípios cortados pela rodovia (considerando a sua área total e não apenas o perímetro urbano);

ii) os municípios distantes até $50 \mathrm{~km}$ da rodovia;

\footnotetext{
${ }^{1}$ Esses municípios são, na verdade, unidades territoriais de análise compostas por municípios de origem comum.
} 
iii) os municípios entre 50 e $100 \mathrm{~km}$ da rodovia;

iv) os municípios entre 100 e $200 \mathrm{~km}$ da rodovia.

A Figura 2 apresenta a definição das áreas de análise da Belém-Teresina e da Cuiabá-Porto Velho, bem como as sedes municipais existentes em 1970 e em 2000. No caso dessa última rodovia, quando se aumenta a distância das sedes dos municípios de $50 \mathrm{~km}$ para $100 \mathrm{~km}$, não há acréscimo de municípios.

A área de análise mais ampla da rodovia Belém-Teresina é composta por 218 municípios, tendo como referência a malha municipal 1970. Desse total, 32 são efetivamente atravessados pela rodovia, 38 são vizinhos da rodovia distantes até $50 \mathrm{~km}, 63$ localizam-se entre $50 \mathrm{~km}$ e $100 \mathrm{~km}$ da rodovia, e os demais 85 estão entre 100 e $200 \mathrm{~km}$ da rodovia.

Pela Figura 2 é possível notar que grande parte das sedes dos municípios existentes na área da Belém-Teresina, em 1970, estava localizada ao longo do litoral, de forma que, a rodovia, quando implantada, atravessava espaços menos povoados e áreas predominantemente rurais dos municípios. A partir da construção da rodovia, como veremos a seguir, há um deslocamento de pessoas dessas áreas de ocupação mais antiga em direção ao eixo rodoviário, o que dá origem a novos povoados, mais tarde, elevados à categoria de municípios.

Na área da Cuiabá-Porto Velho fica evidente, pelo reduzido número de sedes de municípios existentes em 1970, que a rodovia cortava um território ainda pouco ocupado. A área de análise total da rodovia é composta por 27 municípios, dos quais 13 são cortados pela rodovia, 7 estão distantes até $50 \mathrm{~km}$ da rodovia e 7 estão entre 100 e $200 \mathrm{~km}$ da rodovia.

Especialmente no caso de Rondônia, onde existiam, até 1977, apenas os municípios de Porto Velho e Guajará-Mirim, a construção e posterior pavimentação da rodovia foi utilizada, de fato, como um mecanismo de ocupação da região.

Com a rodovia, há uma ruptura da estrutura espacial centrada em Guajará-Mirim e Porto Velho e a criação desordenada de aglomerados urbanos ao longo do eixo rodoviário Cuiabá-Porto Velho. Embora já na década de 1970, além do extrativismo mineral e vegetal, Rondônia tivesse descoberto a vocação agrícola, dada à existência de terras com alguma fertilidade, o acesso à região ainda era difícil, a rodovia era não pavimentada e com trechos submersos durante parte do ano. A pavimentação da BR-364, entre 1983 e 1984, teve um papel estratégico para consolidação do desenvolvimento da região de Rondônia e Norte do Mato Grosso. ${ }^{2}$

A evolução do número de municípios nas áreas das rodovias Belém-Teresina e Cuiabá-Porto, apresentada Tabela 1, reforça as evidências da Figura 2.

A exemplo do que ocorre no Nordeste, como um todo, não há criação de municípios na área da Belém-Teresina, entre 1970 e 1980, em virtude, inclusive de restrições da legislação federal, datada de 1967, que impunha, entre outras restrições, uma população mínima de 10 mil habitantes e a existência de centro urbano constituído para que pudesse ser criado um novo município (IBAM, 2006). A maior parte dos municípios foi criada, de fato, entre 1991 e 2000, quando foram implantados cento e quinze municípios, sendo quatorze no Pará, quarenta e um no Piauí e sessenta no Maranhão, desses, trinta foram criados a partir de municípios cortados pela rodovia.

De outro lado, o efeito da consolidação/pavimentação da Cuiabá-Porto Velho sobre a formação de novos municípios parece ser mais evidente, principalmente quando se analisa a região pertencente ao Estado de Rondônia.

$\mathrm{Na}$ área da rodovia Cuiabá-Porto Velho, foram criados, de 1970 ao ano 2000, cento e um novos municípios, sendo oitenta ao longo do eixo rodoviário. 0 então território ${ }^{3}$ de Rondônia era dividido, como já foi dito, em dois municípios em 1970, Guajará-Mirim e Porto Velho, criados em 1943 e, ainda

\footnotetext{
${ }^{2}$ Mais tarde, em 1985, é aprovado um empréstimo junto ao Banco Mundial para pavimentação do trecho da BR-364, que liga Porto Velho, em Rondônia, a Rio Branco, no Acre.

${ }^{3} \mathrm{~A}$ emancipação do território de Rondônia à Unidade da Federação ocorre apenas em 1981.
} 


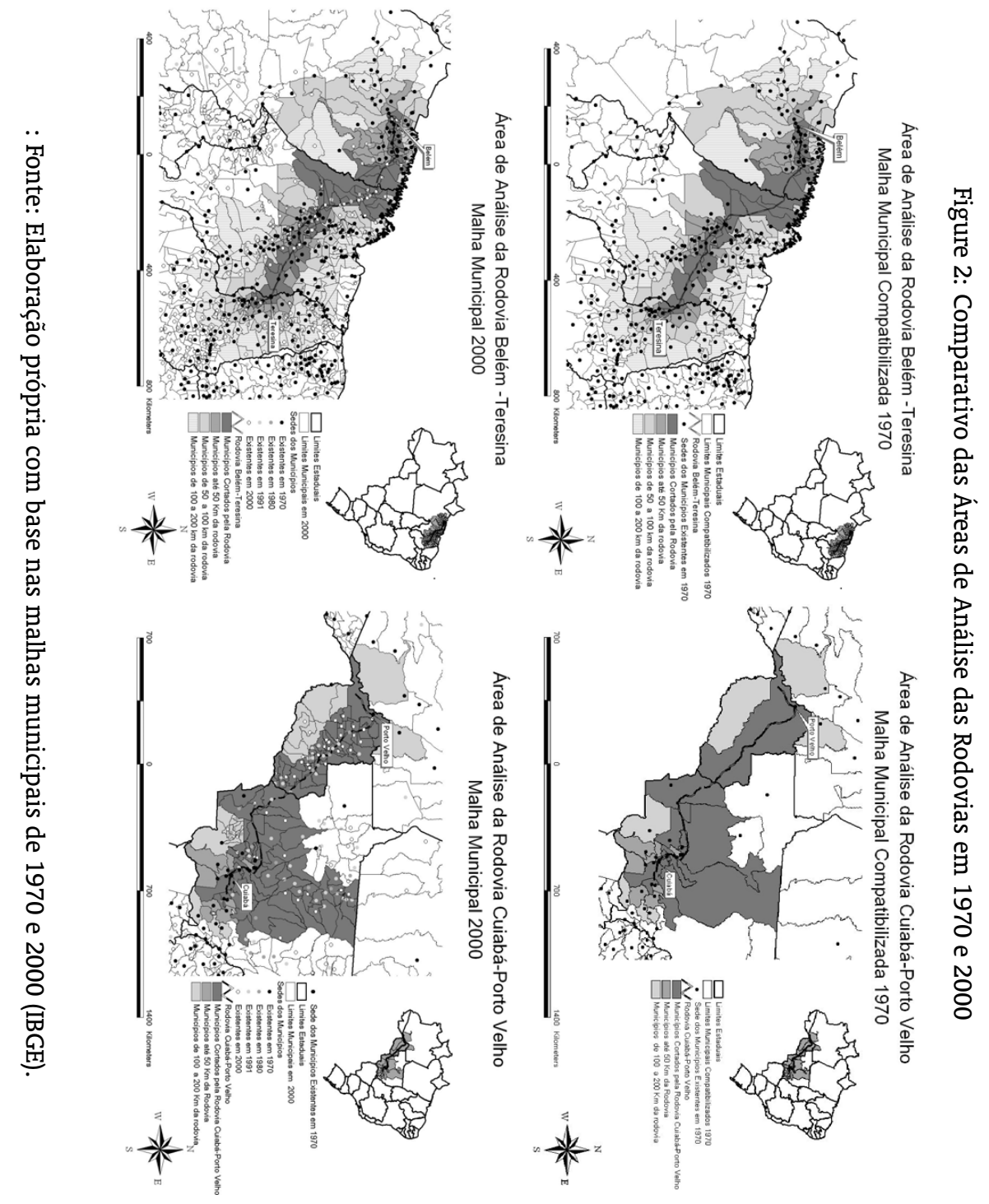


hoje, os de maior área territorial. Em 1980, ainda eram apenas sete municípios. Em 1977, foram criados Ariquemes, Ji-Paraná, Cacoal, Pimenta Bueno e Vilhena, todos atravessados pela BR-364. Ainda antes da pavimentação da rodovia são instalados mais seis municípios Colorado do Oeste, Espigão do Oeste, Presidente Médici, Ouro Preto do Oeste, Jaru e Costa Marques.

Table 1: Evolução no Número de Municípios na Área Total da Rodovia Belém-Teresina e da Cuiabá-Porto Velho, Estados, Região e Brasil

\begin{tabular}{lcccc}
\hline & 1970 & 1980 & 1991 & 2000 \\
\hline Área da Rodovia Belém-Teresina (BR-316) & 218 & $218(0 \%)$ & $229(5 \%)$ & $344(50 \%)$ \\
\hline Municípios da Rodovia & 32 & $32(0 \%)$ & $34(6 \%)$ & $66(94 \%)$ \\
Municípios até $50 \mathrm{~km}$ & 38 & $38(0 \%)$ & $42(10 \%)$ & $57(36 \%)$ \\
Municípios entre 50 e $100 \mathrm{~km}$ & 63 & $63(0 \%)$ & $67(6 \%)$ & $91(36 \%)$ \\
Municípios entre 100 e $200 \mathrm{~km}$ & 85 & $85(0 \%)$ & $86(1 \%)$ & $130(51 \%)$ \\
\hline Área da Rodovia Cuiabá-Porto Velho (BR-364) & 28 & $48(71 \%)$ & $90(87 \%)$ & $138(53 \%)$ \\
\hline Municípios da Rodovia & 14 & $27(93 \%)$ & $61(125 \%)$ & $103(69 \%)$ \\
Municípios vizinhos até $50 \mathrm{~km}$ & 7 & $8(14 \%)$ & $8(0 \%)$ & $9(12 \%)$ \\
Municípios vizinhos até $200 \mathrm{~km}$ & 7 & $13(86 \%)$ & $21(62 \%)$ & $26(24 \%)$ \\
\hline Norte & 195 & $205(5 \%)$ & $298(45 \%)$ & $449(51 \%)$ \\
\hline Nordeste & 1375 & $1375(0 \%)$ & $1509(10 \%)$ & $1787(18 \%)$ \\
\hline Centro-Oeste & 306 & $334(9 \%)$ & $379(13 \%)$ & $446(18 \%)$ \\
\hline Brasil & 3981 & $3991(0,02 \%)$ & $4991(25 \%)$ & $5507(10 \%)$ \\
\hline
\end{tabular}

: Fonte: Elaboração própria a partir dos Censos Demográficos (IBGE). A Tabela apresenta o número de municípios existentes nas áreas das rodovias nos últimos quatro Censos Demográficos, segundo a sua localização em relação às mesmas, nas Regiões Norte, Nordeste, Centro-Oeste, regiões por onde passam as rodovias, e no Brasil. Entre parênteses está reportada a variação percentual no total de municípios de um Censo Demográfico para outro. Nos Censos de 1970 e 1980, estão incluídos, no Centro-Oeste, os municípios pertencentes ao atual Estado do Tocantins, antes parte de Goiás. O total de municípios do Brasil, em 1970, Inclui os municípios do antigo Estado da Guanabara, atual município do Rio de Janeiro e cidades satélites de Brasília (Brazlândia, Taguatinga, Paranoá, Planaltina, Sobradinho, Jardim e Gama).

No Estado do Mato Grosso, por sua vez, também parece ter havido algum tipo de urbanização decorrente da pavimentação da rodovia. Foram implantados, entre 1980 e 1991, dezoito municípios na área atravessada pela rodovia e mais quatro municípios distantes até $200 \mathrm{~km}$. Entre 1991 e 2000 foram criados, no Estado, mais dezesseis municípios na área de análise da Cuiabá-Porto Velho.

Desse modo, embora grande parte da população tenha se deslocado para a região do eixo rodoviário da BR-364 em busca de terras com aptidão agrícola e das facilidades oferecidas pelo Governo para produção rural, a chegada dos novos contingentes populacionais parece ter levado a uma maior urbanização da região, com baixa densidade urbana, ainda no início da década de 1980.

Comparativamente ao que ocorreu na área da rodovia Belém-Teresina, cujo processo de ocupação e urbanização é bem mais antigo, o fenômeno de aumento da densidade urbana, expresso pela instalação de novas sedes municipais, parece ter sido bem mais intenso na região de Rondônia e Mato Grosso. Retornando à Figura 2, é possível visualizar as alterações ocorridas nas malhas municipais na área das duas rodovias, entre 1970 e 2000 , com a evolução no número de sedes de municípios existentes nos 
quatro últimos censos demográficos. No caso da Cuiabá-Porto Velho, a maior parte dos municípios criados seguindo o eixo da rodovia localiza-se em Rondônia. Os municípios criados em Mato Grosso estão na direção leste, seguindo prioritariamente o eixo da rodovia Cuiabá-Santarém (BR-163), região onde se localizam os solos mais férteis e, por conseguinte, a agricultura em larga escala.

Fato é que, há uma tendência, tanto na área de análise de Belém-Teresina, como da Cuiabá-Porto Velho, em maior ou menor escala, a que sejam criados novos municípios ao longo dos eixos rodoviários, embora esse processo de instalação de municípios ocorra de maneira gradual, acompanhando o desenvolvimento da infra-estrutura de serviços local e as alterações na legislação para criação/emancipação de municípios.

Mas, o que faz com que esses novos municípios sejam criados? Uma resposta natural é o aumento da população na região. Mas o que explica esse incremento populacional? Admitindo que não houve mudanças bruscas nas taxas de fecundidade e mortalidade, uma explicação seria a migração de pessoas em direção as áreas próximas às rodovias. Esta subseção traz alguns referenciais teóricos que associam migração e custos de transporte e apresenta os dados dos movimentos migratórios nas áreas de análise da Belém-Teresina e Cuiabá-Porto Velho na década em que foram realizadas as obras rodoviárias.

A maior parte das estimações empíricas de migração bruta, segundo Greenwood (1975), baseia-se nos modelos do tipo gravitacional, cuja hipótese é a de que a migração é diretamente relacionada ao tamanho relevante das populações de origem e destino e inversamente relacionada à distância. Uma das implicações desses modelos é que a distância aparece como uma forte restrição à migração. $O$ fato de a migração diminuir substancialmente com o aumento da distância é porque a mesma funciona como uma proxy dos custos de acessibilidade e psíquicos de deslocamento, bem como da disponibilidade de informação.

As obras de melhorias na infra-estrutura rodoviária, nesse sentido, propiciam alterações nos fluxos migratórios já que representam uma redução nas distâncias entre as localidades e, consequentemente, um melhor acesso aos mercados regionais e nacionais de bens e serviços.

Para analisar os movimentos migratórios decorrentes das duas obras viárias analisadas, realizamos o levantamento dos fluxos migratórios a partir dos microdados dos Censos Demográficos de 1980, no caso da rodovia Belém-Teresina, e, de 1991, para a análise da Cuiabá-Porto Velho, considerando-se apenas os chefes de família residentes em domicílios particulares permanentes.

Os migrantes são definidos como aqueles que residem há menos de 10 anos no município onde se situa o domicílio na data do Censo. Para se obter o total de imigrantes e emigrantes ao longo da década, são utilizadas as informações sobre o município de residência, tempo de residência nesse município, a partir do qual se obtém a época da migração, e o município de residência anterior.

Um problema do quesito "tempo de residência nesse município", no Censo Demográfico de 1980, é que aparecem na mesma categoria os que residem de 6 a 9 anos no município. A alternativa adotada foi distribuir os migrantes uniformemente nos quatro anos.

No caso do "município de residência anterior", o informante declara apenas o país, quando morava anteriormente no exterior, e pode não informar o município de residência anterior, mas apenas a Unidade da Federação, no caso da migração interna. Isso faz com que o total de emigrantes possa estar subestimado pela não declaração do município anterior. Contudo, é a única informação disponível no Censo de 1980, que não possui informação de migração com data fixa.

São imigrantes nas áreas das rodovias aqueles que residem há menos de 10 anos em um município pertencente à área definida como de análise dos eixos rodoviários analisados. Já os emigrantes são todos os residentes há menosde 10 anos em qualquer município do Brasil, cujo município de residência anterior informado faça parte da área da rodovia analisada. Como, na verdade, trabalha-se com uma malha municipal compatibilizada, não foram considerados como migrantes aqueles cujo município anterior é igual ao município atual, ou seja, desconsidera-se a migração que ocorre entre os municípios que foram unidos para que fosse possível trabalhar com os quatro últimos censos demográficos.

No que diz respeito à área de análise da rodovia Belém-Teresina, por estar relativamente próxima ao litoral nordestino, esta já era uma área com alguma densidade urbana na ocasião da abertura da 
rodovia, embora cumpra destacar que o Maranhão e Piauí, ainda na década de 90 , estavam entre os Estados nordestinos com menor nível de urbanização relativa (Martine, 1995).

O gráfico 1 da Figura 3 aponta para um aumento do saldo migratório, diferença entre imigrantes e emigrantes, nessa área, a partir de 1976/77, época em que a rodovia foi entregue ao tráfego. Entre 1975 e 1976 eram cerca de 19 mil migrantes contra pouco mais 23 mil, no período subseqüente.

Os fluxos migratórios dos municípios da área da rodovia Cuiabá-Porto Velho também parecem sofrer influência da obra viária para melhoria da ligação entre as capitais regionais. Até o início da década de 70, o Estado de Rondônia, na fronteira norte, ainda território federal, era, como afirmam Margulis (1991) e Martine (1995), um grande vazio demográfico. Mato Grosso, localizado na Região Centro-Oeste, por sua vez, já apresentava alguma ocupação de fronteira.

Embora, em 1980, a Região Norte tenha tido uma taxa líquida de imigração inferior às das regiões Sudeste e, especialmente, Centro-Oeste, Rondônia apresentou, para o mesmo período, taxas de imigração superiores às de ambas as regiões (Buarque et al., 1995). É sabido que os esforços de colonização dirigida em Rondônia, a partir da construção e da posterior pavimentação da BR-364 (foco dessa análise), mesmo tendo sido um relativo fracasso quanto à fixação dos colonos, foram responsáveis pelas maiores taxas de crescimento ao longo das décadas de 70 e 80.

Como o foco de análise desse trabalho é a pavimentação da Cuiabá-Porto Velho no início da década de oitenta, os dados de migração, aqui apresentados, referem-se apenas ao processo migratório ocorrido ao longo da década de 1980. Pela Figura 3, é possível verificar que, nos municípios da área da rodovia Cuiabá-Porto Velho, excluindo as duas capitais, há um claro aumento no número de imigrantes, comparativamente aos emigrantes, a partir da pavimentação desse trecho rodoviário, elevando o patamar do saldo migratório, de 5.802, entre 1983 e 1984, para 7.430 , de 1984 a 1985 , contudo, já no período seguinte começa a haver um declínio do saldo migratório, que pode ser resultado das pressões fundiárias surgidas nas áreas mais próximas da rodovia, que levaram a população a adentrar para áreas mais distantes da Amazônia. A partir de 1988, há um novo aumento do saldo migratório, que, no início da década de 90 sofre uma queda acentuada.

Quanto à origem e ao tipo de migração que ocorrem nas áreas da Belém-Teresina e da Cuiabá-Porto Velho, nos respectivos momentos de construção e pavimentação das rodovias, comparando-se os gráfi$\cos 2$ e 5 e os gráficos 3 e 6 , fica claro que a maior parte dos migrantes, no primeiro caso, são oriundos da própria área de análise da rodovia e realizam a migração do tipo rural-rural, isto é, são pessoas residentes em áreas rurais da rodovia que migram para outras áreas rurais distantes até $200 \mathrm{~km}$ da rodovia. Já na área da Cuiabá-Porto Velho os migrantes, em sua maior parte, vêm de regiões distantes mais de $200 \mathrm{~km}$ da rodovia. Em 1984/1985, os migrantes inter-regionais correspondiam à cerca de 75\% do total de imigrantes na área da rodovia, excluindo as capitais. Com a ocupação crescente do eixo rodoviário, essa parcela vai, aos poucos, decrescendo e, entre 1990 e 1991, era de apenas 52\%. Além disso, diferentemente do que ocorre em Belém-Teresina, a maior proporção da migração é do tipo urbano-urbano.

Muito dessa diferença entre as duas rodovias decorre do contexto histórico em que foram realizadas as obras. Na década de 1970, quando foi construída a Belém-Teresina, grande parte do país, sobretudo as regiões Norte e Nordeste, ainda era predominantemente rural. O percentual de população urbana no Brasil, em 1970, era de apenas 55,94\%, contra 67,59\%, em 1980 e 75,59\% em 1991. No Norte e Nordeste, o percentual de população rural, em 1970, era, respectivamente, cerca de $55 \%$ e $58 \%$ e, em 1980 , ainda era de pouco menos de $50 \%$ nas duas regiões. De outro lado, o percentual da população urbana no Centro-Oeste passou de 67,78\% para 81,28\% entre 1980 e 1991.

\subsection{Estratégia de estimação}

A construção de uma obra rodoviária, ou qualquer outro tipo ligação entre dois lugares, objetiva, entre outras coisas, a redução do custo de transporte, com consequente diversificação produtiva e intensificação do comércio, viabilizada pela ampliação do acesso a mercados produtores e consumidores. 


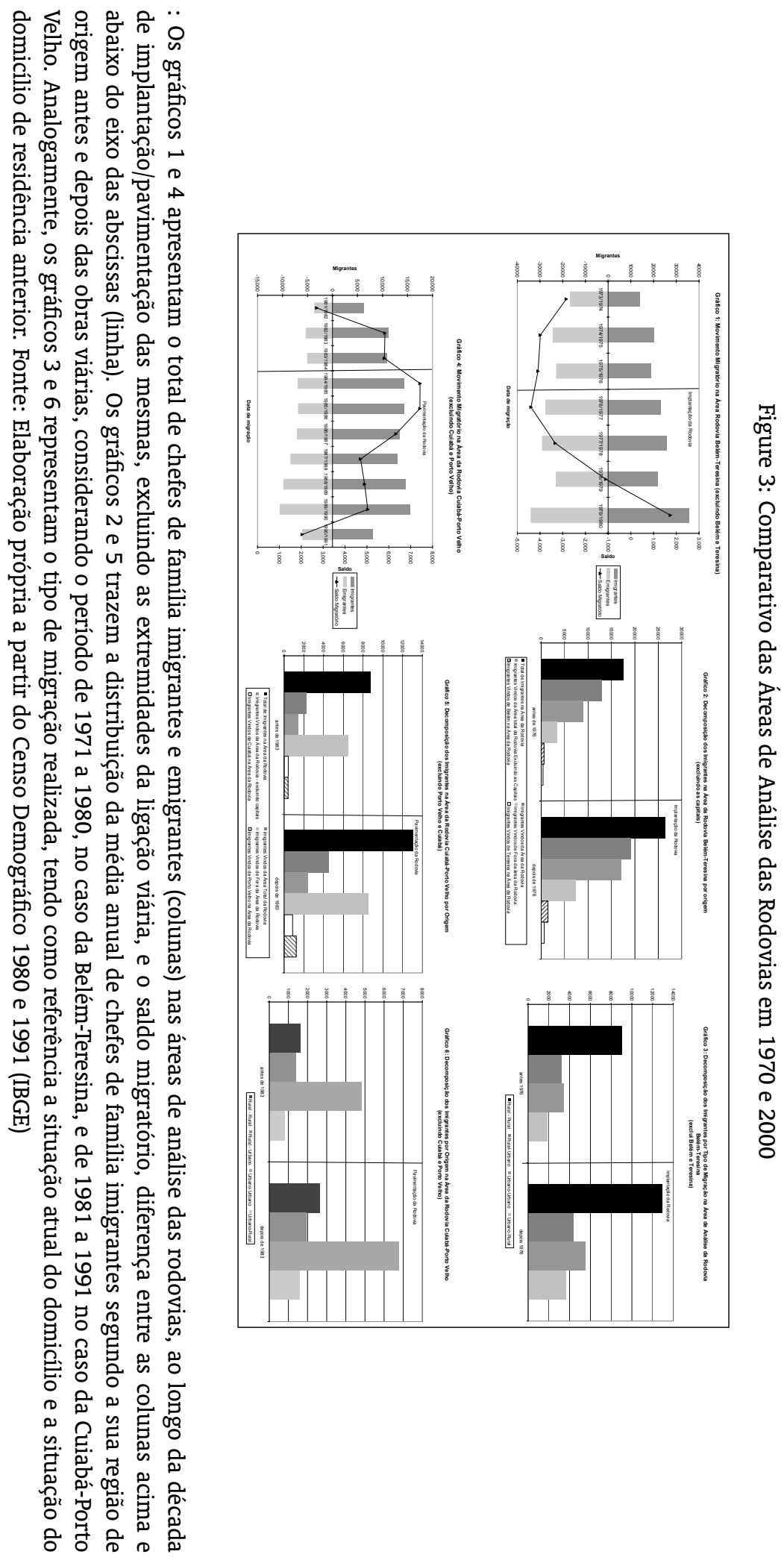


Logo, só faz sentido pensar em melhorar o acesso entre duas localidades caso já exista algum tipo de desenvolvimento em pelo menos uma delas.

É de se esperar, portanto, que as extremidades e, eventualmente, alguns municípios ao longo de eixos rodoviários sejam regiões mais desenvolvidas, com algum tipo de produção em escala comercial e grau de urbanização mesmo antes da existência da rodovia.

Especialmente nos casos das duas rodovias que estamos analisando é patente a diferença entre o grau de urbanização das extremidades da rodovia e os demais municípios da região. Nos dois casos, trata-se da ligação entre duas cidades que são capitais de Unidades da Federação, o que por si só, já garante uma dinâmica diferenciada. A taxa de urbanização em Belém, por exemplo, é de praticamente $100 \%$ enquanto que a média da região da área de análise da rodovia é de apenas $46,72 \%$. Em Porto Velho, essa taxa fica em torno de $82 \%$ em contraposição a média da área de análise da rodovia Cuiabá-Porto Velho de apenas 59\%.

Dessa maneira, para focalizar o exercício em unidades territoriais em estágios iniciais de urbanização, a análise da relação entre urbanização e renda restringirá a amostra dos municípios pertencentes à área de análise das rodovias àqueles que foram criados posteriormente às obras analisadas, ou seja, no caso da Belém-Teresina, municípios criados após 1976 e, da Cuiabá-Porto Velho, após 1983. Com isso, estamos analisando um processo de urbanização de certa forma exógeno ao aumento de renda, decorrente primordialmente de uma redução nos custos de transporte.

A estratégia empírica adotada consiste em estimar para os indivíduos com idade acima de 10 anos, residentes em municípios criados após a construção da Belém-Teresina e em seguida a pavimentação da Cuiabá-Porto Velho, uma equação de rendimento incluindo variáveis individuais e do município, como forma de estabelecer os mecanismos por meio dos quais se dá a relação entre urbanização e rendimento.

Desse modo, busca-se mensurar tanto a correlação entre a residência ou não do indivíduo no meio urbano com o seu rendimento individual, como também a correlação desse com o fato do indivíduo residir em uma área mais urbanizada.

As amostras das áreas de análise da Belém-Teresina e Cuiabá-Porto Velho são compostas por, respectivamente, 73.902 indivíduos distribuídos em 126 municípios, e 29.702 indivíduos distribuídos em 39 municípios.

\section{BASE DE DADOS}

Como estamos analisando a construção de rodovias em dois contextos distintos, são construídas duas bases de dados a partir dos microdados do Censo Demográfico 2000, uma com informações de residentes em municípios ao longo da Belém-Teresina e outra para residentes em municípios ao redor da Cuiabá-Porto Velho, conforme a delimitação apresentada na Figura 2.

As bases de dados são compostas por variáveis em dois níveis: individual e do município, apresentadas na Tabela 2. A variável renda, descrita na Tabela 2 , é a variável dependente das estimações apresentadas na Tabela 5. Como fatores determinantes temos uma variável de urbanização no nível individual e outro no nível local, respectivamente, uma dummy para residência no meio urbano e a taxa de urbanização.

As demais variáveis descritas na Tabela 2 são variáveis de controle que objetivam apontar os canais pelos quais a urbanização poderia afetar o rendimento individual.

\section{RESULTADOS}

Os resultados são apresentados em 2 etapas. Na primeira etapa, são reportadas e analisadas as estimativas da relação entre urbanização e distância às rodovias considerando a totalidade dos municípios na área ao redor das rodovias Cuiabá-Porto Velho e Belém-Teresina (subseção 4.1). Já na segunda etapa 
Table 2: Composição da Base de Dados

\begin{tabular}{|c|c|c|}
\hline Grupo & Individuais & Municípios \\
\hline Renda & $\begin{array}{l}\text { Rendimento total: incluindo rendimento de } \\
\text { todos os trabalhos e de outras fontes, como } \\
\text { doações, pensões, aluguéis, entre outros }\end{array}$ & \\
\hline Urbanização & Dummy reside no meio rural ou urbano & $\begin{array}{l}\text { Taxa de Urbanização (Total da população res- } \\
\text { idente na área urbana dividido pela popu- } \\
\text { lação total) }\end{array}$ \\
\hline Demografia & $\begin{array}{l}\text { Idade } \\
\text { Idade ao quadrado (como proxy para exper- } \\
\text { iência) } \\
\text { Dummy Sexo } \\
\text { Dummy Raça (preto/pardo) } \\
\text { Estado civil } \\
\text { Dummy se nasceu ou não no município } \\
\text { Dummy se é migrante ou não (mora há } \\
\text { menos de } 10 \text { anos no município atual) }\end{array}$ & $\begin{array}{l}\text { Percentual da população com } 15 \text { anos ou } \\
\text { mais } \\
\text { Percentual da população com } 25 \text { anos ou } \\
\text { mais } \\
\text { População } \\
\text { Densidade demográfica (população total di- } \\
\text { vidida pela área total) } \\
\text { Percentual de Imigrantes no Município }\end{array}$ \\
\hline Educação & Dummy sabe ler e escrever & $\begin{array}{l}\text { Médias de anos de estudo da população com } \\
10 \text { anos ou mais } \\
\text { Média de anos de estudo da população com } \\
15 \text { anos ou mais } \\
\text { Média de anos de estudo da população com } \\
25 \text { anos ou mais } \\
\text { Percentual que sabe ler e escrever }\end{array}$ \\
\hline $\begin{array}{l}\text { Trabalho e } \\
\text { Estrutura } \\
\text { Produtiva }\end{array}$ & $\begin{array}{l}\text { Dummy se está ocupado ou não } \\
\text { Total de horas trabalhadas } \\
\text { Dummy de atividade (13 grupos) } \\
\text { Dummy de categoria ocupacional (10 gru- } \\
\text { pos) } \\
\text { Dummy de posição na ocupação (5 grupos) }\end{array}$ & $\begin{array}{l}\text { Taxa de ocupação } \\
\text { Média de horas trabalhadas } \\
\text { Proxy para produtividade (razão entre total } \\
\text { de rendimentos e o total de horas trabal- } \\
\text { hadas) } \\
\text { Percentual de ocupados na agropecuária } \\
\text { Índice Herfindahl (somatório do quadrado } \\
\text { dos percentuais) - exceto a agropecuária } \\
\text { Percentual de ocupados com carteira assi- } \\
\text { nada }\end{array}$ \\
\hline Infra-Estrutura & $\begin{array}{l}\text { Dummy reside em domicílio com: } \\
\text { Telefone } \\
\text { Rede geral de esgotamento sanitário } \\
\text { Água canalizada } \\
\text { Rede geral de abastecimento de água } \\
\text { Iluminação elétrica }\end{array}$ & $\begin{array}{l}\text { Percentual de pessoas em domicílios com: } \\
\text { Telefone } \\
\text { Rede geral de esgotamento sanitário } \\
\text { Água canalizada } \\
\text { Rede geral de abastecimento de água } \\
\text { Iluminação elétrica }\end{array}$ \\
\hline
\end{tabular}

: Fonte: Elaboração própria. A Tabela apresenta descrição das variáveis individuais e municipais incluídas nas estimações apresentadas na Tabela 5. As variáveis estão divididas por grupo, sendo que, para cada um dos grupos, são definidas variáveis do indivíduo e indicadores para o município. 
(subseções 4.2 e 4.3), é feita a restrição da amostra, ou seja, são considerados apenas os municípios criados após a pavimentação da Cuiabá-Porto Velho e a construção da Belém-Teresina.

\subsection{Urbanização e distância às rodovias}

De modo a complementar as informações anteriores sobre aumento da urbanização, via criação de cidades nas proximidades das rodovias, esta subseção mostra que tal aumento pode ser percebido também pela correlação entre a distância à rodovia e indicadores de densidade e infra-estrutura de serviços públicos locais.

Como foi destacado na subseção 2.2, muitos dos municípios criados no Estado do Mato Grosso seguiram a direção leste, no sentido da rodovia Cuiabá-Santarém, logo, para melhorar a identificação do exercício, vamos, a partir deste ponto, excluir os municípios desse Estado da área de análise da rodovia Cuiabá-Porto Velho.

A Tabela 3 apresenta uma síntese das correlações obtidas por meio de regressões de mínimos quadrados ordinários tendo como variáveis dependentes indicadores selecionados e como variável explicativa o logaritmo natural da distância à rodovia. Na área de ambas as rodovias, para todos os indicadores, o coeficiente do logaritmo natural da distância à rodovia é negativo e significativo.

$\mathrm{Na}$ área de análise da Belém-Teresina verifica-se, pelo Painel $\mathrm{A}$ da Tabela 3, que, se a distância à rodovia aumenta em 1\%, o percentual da população urbana reduz, em média, 0,038 pontos percentuais. Ocorre também um decréscimo na densidade urbana e população total à medida que os municípios se distanciam da rodovia. Um aumento de $1 \%$ na distância à rodovia corresponde a uma redução média de $0,2 \%$ na densidade demográfica e de $0,07 \%$ na população total.

Ainda com referência ao Painel A da Tabela 3, verifica-se uma correlação negativa e significativa entre o percentual de atendidos por serviços públicos de infra-estrutura básica e a distância à rodovia. Aumentando, por exemplo, a distância à rodovia em $1 \%$, o percentual de residentes em domicílios com iluminação elétrica reduz, em média, 0,034 pontos percentuais.

Comparando-se as estimativas de R2 para os modelos com as várias medidas de urbanização para a região da rodovia Belém-Teresina, o melhor ajuste é para variável percentual de residentes em domicílios com rede geral de esgotamento sanitário $(0,47)$. Um aumento de $1 \%$ na distância à rodovia, representa, em média, uma redução de 0,021 pontos percentuais nessa taxa.

No caso da Cuiabá-Porto Velho (Painel B da Tabela 3), de um modo geral, a distância à rodovia consegue explicar melhor o comportamento dos diversos indicadores. As correlações são ainda mais acentuadas ou bem próximas aos resultados da Belém-Teresina.

Um aumento de cerca de $1 \%$ na distância à rodovia, por exemplo, está associado a uma redução média de 0,051 pontos percentuais no percentual da população urbana, contra apenas 0,038 pontos percentuais no caso da Belém-Teresina. A diferença mais marcante aparece na regressão do logaritmo da população total, o valor do coeficiente da variável $L N$ da distância à rodovia era de apenas -0,069 significativo a $5 \%$ no caso anterior; para a Cuiabá-Porto Velho, o resultado encontrado é de $-0,253$ significativo a $1 \%$. Nessa rodovia, um município $1 \%$ mais distante apresenta, em média, uma população $0,25 \%$ menor, indicando que existe uma maior aglomeração de pessoas em torno da rodovia.

Dentre os indicadores de infra-estrutura, diferentemente do que ocorre na Belém-Teresina, a maior associação da proximidade à rodovia é com o percentual de residentes em domicílios com rede geral de abastecimento. Um aumento em torno de $1 \%$ na distância à rodovia representa uma redução média de 0,061 pontos percentuais nesse indicador.

Acrescentando os resultados desta subseção ao aumento no número de municípios observado nas regiões analisadas, pode-se dizer que, de fato, existe uma correlação entre o processo de urbanização ocorrido nas regiões de análise da Belém-Teresina e Cuiabá-Porto Velho e, respectivamente, a construção e pavimentação das rodovias. 
Table 3: Regressão OLS Variáveis Selecionadas e $L N$ da Distância à Rodovia

\begin{tabular}{|c|c|c|c|c|c|c|c|c|}
\hline \multicolumn{9}{|c|}{ A: Área de Análise da Rodovia Belém-Teresina } \\
\hline & $\begin{array}{r}\text { Percentual } \\
\text { da } \\
\text { População } \\
\text { Urbana }\end{array}$ & $\begin{array}{r}N \text { da } \\
\text { População } \\
\text { Total }\end{array}$ & $\begin{array}{r}L N \text { da } \\
\text { Densidade } \\
\text { Demográ- } \\
\text { fica }\end{array}$ & $\begin{array}{r}\% \text { em } \\
\text { Domicílios } \\
\text { com } \\
\text { Telefone }\end{array}$ & $\begin{array}{r}\% \text { em } \\
\text { Domicílios } \\
\text { com } \\
\text { Iluminação } \\
\text { Elétrica }\end{array}$ & $\begin{array}{r}\% \text { em } \\
\text { Domicílios } \\
\text { com Água } \\
\text { Canalizada }\end{array}$ & $\begin{array}{r}\% \text { em } \\
\text { Domicílios } \\
\text { com } \\
\text { Esgota- } \\
\text { mento } \\
\text { Sanitário }\end{array}$ & $\begin{array}{r}\% \text { em } \\
\text { Domicílios } \\
\text { com Rede } \\
\text { Geral de } \\
\text { Abasteci- } \\
\text { mento }\end{array}$ \\
\hline $\begin{array}{r}L N \text { da } \\
\text { Distância à } \\
\text { Rodovia }\end{array}$ & $-0,038^{3}$ & $-0,069^{2}$ & $-0,207^{3}$ & $-0,008^{3}$ & $-0,034^{3}$ & $-0,026^{3}$ & $-0,021^{3}$ & $-0,014^{1}$ \\
\hline $\begin{array}{c}\text { Dummies } \\
U F\end{array}$ & $\begin{array}{r}(0,007) \\
\operatorname{sim}\end{array}$ & $\begin{array}{r}(0,032) \\
\text { sim }\end{array}$ & $\begin{array}{r}(0,034) \\
\text { sim }\end{array}$ & $\begin{array}{r}(0,003) \\
\text { sim }\end{array}$ & $\begin{array}{r}(0,007) \\
\operatorname{sim}\end{array}$ & $\begin{array}{r}(0,008) \\
\operatorname{sim}\end{array}$ & $\begin{array}{r}(0,007) \\
\text { sim }\end{array}$ & $\begin{array}{r}(0,008) \\
\text { sim }\end{array}$ \\
\hline Constante & $\begin{array}{l}0,436^{3} \\
(0,024)\end{array}$ & $\begin{array}{r}10,025^{3} \\
(0,110)\end{array}$ & $2,757^{3}$ & $\begin{array}{l}0,049^{3} \\
(0,009)\end{array}$ & $\begin{array}{l}0,636^{3} \\
(0,022)\end{array}$ & $\begin{array}{l}0,447^{3} \\
(0,026)\end{array}$ & $\begin{array}{l}0,868^{3} \\
(0,025)\end{array}$ & $\begin{array}{l}0,342^{3} \\
(0,027)\end{array}$ \\
\hline $\mathrm{N}$ & 343 & 343 & 343 & 343 & 343 & 343 & 343 & 343 \\
\hline $\mathrm{R}^{2}$ & 0,08 & 0,19 & 0,13 & 0,03 & 0,08 & 0,09 & 0,47 & 0,06 \\
\hline \multicolumn{9}{|c|}{ B: Área de Análise da Rodovia Cuiabá-Porto Velho } \\
\hline & $\begin{array}{r}\text { Percentual } \\
\text { da } \\
\text { População } \\
\text { Urbana }\end{array}$ & $\begin{array}{r}N \text { da } \\
\text { População } \\
\text { Total }\end{array}$ & $\begin{array}{r}L N \text { da } \\
\text { Densidade } \\
\text { Demográ- } \\
\text { fica }\end{array}$ & $\begin{array}{r}\% \text { em } \\
\text { Domicílios } \\
\text { com } \\
\text { Telefone }\end{array}$ & $\begin{array}{r}\% \text { em } \\
\text { Domicilios } \\
\text { com } \\
\text { Iluminação } \\
\text { Elétrica }\end{array}$ & $\begin{array}{r}\% \text { em } \\
\text { Domicílios } \\
\text { com Água } \\
\text { Canalizada }\end{array}$ & $\begin{array}{r}\% \text { em } \\
\text { Domicílios } \\
\text { com } \\
\text { Esgota- } \\
\text { mento } \\
\text { Sanitário }\end{array}$ & $\begin{array}{r}\% \text { em } \\
\text { Domicílios } \\
\text { com Rede } \\
\text { Geral de } \\
\text { Abasteci- } \\
\text { mento }\end{array}$ \\
\hline $\begin{array}{r}L N \text { da } \\
\text { Distância à } \\
\text { Rodovia }\end{array}$ & $-0,051^{3}$ & $-0,253^{3}$ & $-0,191^{3}$ & $-0,050^{3}$ & $-0,045^{3}$ & $-0,054^{3}$ & $-0,026^{3}$ & $-0,061^{3}$ \\
\hline $\begin{array}{r}\text { Dummies } \\
U F\end{array}$ & $\begin{array}{r}(0,014) \\
\text { sim }\end{array}$ & $\begin{array}{r}(0,055) \\
\text { sim }\end{array}$ & $\begin{array}{r}(0,062) \\
\operatorname{sim}\end{array}$ & $\begin{array}{r}(0,009) \\
\text { sim }\end{array}$ & $\begin{array}{r}(0,010) \\
\text { sim }\end{array}$ & $\begin{array}{r}(0,010) \\
\operatorname{sim}\end{array}$ & $\begin{array}{r}(0,007) \\
\text { sim }\end{array}$ & $\begin{array}{r}(0,011) \\
\text { sim }\end{array}$ \\
\hline Constante & $\begin{array}{l}0,364^{3} \\
(0,038)\end{array}$ & $\begin{array}{l}9,171^{3} \\
(0,145)\end{array}$ & $\begin{array}{l}1,317^{3} \\
(0,162)\end{array}$ & $\begin{array}{l}0,076^{3} \\
(0,023)\end{array}$ & $\begin{array}{l}0,640^{3} \\
(0,025)\end{array}$ & $\begin{array}{l}0,543^{3} \\
(0,026)\end{array}$ & $\begin{array}{l}0,785^{3} \\
(0,020)\end{array}$ & $\begin{array}{l}0,087^{3} \\
(0,029)\end{array}$ \\
\hline $\mathrm{N}$ & 54 & 54 & 54 & 54 & 54 & 54 & 54 & 54 \\
\hline $\mathrm{R}^{2}$ & 0,23 & 0,31 & 0,28 & 0,39 & 0,31 & 0,37 & 0,20 & 0,43 \\
\hline
\end{tabular}

: Fonte: Elaboração própria. A Tabela reporta os resultados das regressões entre várias medidas relacionadas a uma maior urbanização e o logaritmo natural da distância esférica (considerando a curvatura do planeta Terra) da sede do município até o ponto mais próximo da rodovia. Os percentuais estão entre $(0$ e 1$)$. Entre parênteses são apresentados os desvios padrões dos coeficientes. Coeficientes significativos ao nível de $10 \%$ são denotados por $\left({ }^{1}\right)$, a $5 \%$ por $\left({ }^{2}\right)$, e a $1 \%$ por $\left({ }^{3}\right)$. O painel A apresenta os resultados considerando 344 municípios da área de análise da rodovia Belém-Teresina (como é utilizado o logaritmo da distância, tem-se um missing de observação para o município cuja sede é coincidente com o ponto da rodovia, ou seja, a distância é igual a zero). No painel B são considerados 54 municípios pertencentes à área de análise da Cuiabá-Porto Velho, excluindo os municípios do Estado do Mato Grosso, em todas as regressões são incluídas dummies de Unidade da Federação. 


\subsection{Caracterização dos municípios criados a partir da pavimentação da Cuiabá- Porto Velho e da implantação da Belém Teresina}

A Tabela 4 apresenta uma síntese da caracterização dos novos municípios nas áreas de análise das rodovias Cuiabá-Porto Velho e Belém-Teresina por quartil da distribuição da taxa de urbanização, medida pela razão entre a população residente no perímetro urbano, conforme definição da legislação municipal, e a população total.

Table 4: Estatística Descritiva Variáveis Selecionadas Municípios Novos na Área de Análise das Rodovias

\begin{tabular}{|c|c|c|c|c|c|c|c|c|c|c|}
\hline \multirow[b]{2}{*}{ Variáveis } & \multicolumn{5}{|c|}{ (a) Belém-Teresina } & \multicolumn{5}{|c|}{ (b) Cuiabá-Porto Velho } \\
\hline & Total & 1 & 2 & 3 & 4 & Total & 1 & 2 & 3 & 4 \\
\hline Taxa de urbanização & 0,40 & 0,19 & 0,31 & 0,44 & 0,66 & 0,36 & 0,16 & 0,27 & 0,42 & 0,61 \\
\hline População total & 11523 & 9291 & 8644 & 10036 & 18240 & 12267 & 9871 & 9726 & 12745 & 17222 \\
\hline Densidade demográfica & 24,2 & 13,97 & 14,96 & 18,81 & 49,70 & 6,48 & 7,87 & 5,60 & 6,23 & 6,19 \\
\hline Idade média & 24,89 & 24,70 & 24,41 & 26,24 & 24,20 & 24,70 & 24,87 & 24,55 & 24,99 & 24,35 \\
\hline$\%$ da população com 15 anos ou + & 0,62 & 0,62 & 0,60 & 0,63 & 0,61 & 0,64 & 0,65 & 0,64 & 0,65 & 0,64 \\
\hline$\%$ da população com 25 anos ou + & 0,40 & 0,38 & 0,39 & 0,42 & 0,40 & 0,43 & 0,43 & 0,43 & 0,44 & 0,42 \\
\hline \multicolumn{11}{|l|}{ Média de Anos de Estudo } \\
\hline População c/ 10 anos ou + & 2,11 & 1,66 & 2,02 & 2,30 & 2,49 & 3,11 & 2,93 & 2,90 & 3,28 & 3,36 \\
\hline População c/ 15 anos ou + & 2,06 & 1,59 & 1,95 & 2,26 & 2,44 & 3,03 & 2,84 & 2,79 & 3,22 & 3,31 \\
\hline População c/ 25 anos ou + & 1,36 & 0,96 & 1,28 & 1,49 & 1,72 & 2,25 & 2,07 & 2,04 & 2,41 & 2,50 \\
\hline Média do rend. familiar total per capita & 91,41 & 71,72 & 78,18 & 109,87 & 105,92 & 227,00 & 198,90 & 233,03 & 239,37 & 237,77 \\
\hline Média do rend. familiar do trabalho per capita & 160,50 & 115,11 & 135,36 & 187,67 & 204,44 & 394,17 & 366,24 & 376,27 & 404,69 & 433,38 \\
\hline \multicolumn{11}{|l|}{ Percentual de trabalhadores na } \\
\hline Agropecuária & 0,57 & 0,70 & 0,60 & 0,56 & 0,42 & 0,59 & 0,74 & 0,68 & 0,53 & 0,41 \\
\hline Extração & 0,04 & 0,04 & 0,04 & 0,05 & 0,03 & 0,01 & 0,01 & 0,01 & 0,01 & 0,03 \\
\hline Indústria moderna & 0,00 & 0,00 & 0,00 & 0,00 & 0,00 & 0,00 & 0,00 & 0,00 & 0,00 & 0,00 \\
\hline Indústria tradicional & 0,04 & 0,03 & 0,05 & 0,03 & 0,05 & 0,05 & 0,02 & 0,04 & 0,06 & 0,07 \\
\hline Construção civil & 0,03 & 0,02 & 0,03 & 0,03 & 0,04 & 0,02 & 0,02 & 0,02 & 0,03 & 0,04 \\
\hline Serviços públicos & 0,04 & 0,03 & 0,04 & 0,04 & 0,04 & 0,04 & 0,04 & 0,04 & 0,04 & 0,06 \\
\hline Comércio & 0,08 & 0,04 & 0,06 & 0,10 & 0,13 & 0,08 & 0,05 & 0,06 & 0,09 & 0,11 \\
\hline Serviços pessoais & 0,04 & 0,03 & 0,04 & 0,04 & 0,05 & 0,05 & 0,03 & 0,03 & 0,05 & 0,08 \\
\hline Serviços produtivos & 0,02 & 0,01 & 0,02 & 0,01 & 0,03 & 0,02 & 0,01 & 0,01 & 0,02 & 0,03 \\
\hline Serviços distributivos & 0,02 & 0,01 & 0,01 & 0,02 & 0,05 & 0,02 & 0,01 & 0,02 & 0,02 & 0,03 \\
\hline Serviços de ensino e saúde & 0,06 & 0,05 & 0,05 & 0,06 & 0,06 & 0,05 & 0,04 & 0,05 & 0,05 & 0,06 \\
\hline Serviços institucionais & 0,00 & 0,00 & 0,00 & 0,00 & 0,00 & 0,00 & 0,00 & 0,00 & 0,01 & 0,00 \\
\hline Outras atividades & 0,05 & 0,05 & 0,04 & 0,04 & 0,08 & 0,05 & 0,04 & 0,03 & 0,07 & 0,06 \\
\hline Herfindahl de Atividades Não-Agropecuárias & 0.19 & 0.16 & 0.17 & 0.21 & 0.20 & 0.14 & 0.14 & 0.14 & 0.13 & 0.13 \\
\hline$\%$ de imigrantes & 0,17 & 0,13 & 0,14 & 0,17 & 0,24 & 0,29 & 0,24 & 0,33 & 0,29 & 0,30 \\
\hline$\%$ sabe ler e escrever & 0,52 & 0,47 & 0,50 & 0,53 & 0,57 & 0,72 & 0,71 & 0,71 & 0,72 & 0,72 \\
\hline$\%$ de empregados & 0,33 & 0,26 & 0,28 & 0,32 & 0,44 & 0,36 & 0,25 & 0,28 & 0,41 & 0,49 \\
\hline$\%$ de empregadores & 0,01 & 0,00 & 0,00 & 0,01 & 0,01 & 0,02 & 0,01 & 0,01 & 0,02 & 0,01 \\
\hline$\%$ de conta própria & 0,38 & 0,38 & 0,37 & 0,41 & 0,36 & 0,42 & 0,50 & 0,44 & 0,39 & 0,34 \\
\hline$\%$ de não remunerados & 0,29 & 0,35 & 0,34 & 0,26 & 0,19 & 0,21 & 0,23 & 0,27 & 0,18 & 0,15 \\
\hline$\%$ de trabalhadores com carteira assinada & 0,06 & 0,03 & 0,04 & 0,05 & 0,10 & 0,12 & 0,08 & 0,10 & 0,14 & 0,16 \\
\hline$\%$ em dom. c/ telefone & 0,02 & 0,01 & 0,02 & 0,02 & 0,05 & 0,09 & 0,04 & 0,05 & 0,11 & 0,18 \\
\hline$\%$ em dom. c/ iluminação elétrica & 0,65 & 0,47 & 0,60 & 0,73 & 0,78 & 0,66 & 0,64 & 0,55 & 0,72 & 0,74 \\
\hline$\%$ em dom. c/ água canalizada & 0,39 & 0,24 & 0,36 & 0,48 & 0,46 & 0,58 & 0,60 & 0,49 & 0,64 & 0,58 \\
\hline$\%$ em dom. c/ rede de esgotamento sanitário & 0,44 & 0,29 & 0,39 & 0,48 & 0,60 & 0,80 & 0,73 & 0,77 & 0,84 & 0,85 \\
\hline$\%$ em dom. $\mathrm{c} /$ rede de água & 0,31 & 0,18 & 0,30 & 0,40 & 0,33 & 0,12 & 0,06 & 0,08 & 0,13 & 0,23 \\
\hline Total de Observações & 126 & 32 & 31 & 32 & 31 & 39 & 10 & 10 & 10 & 9 \\
\hline
\end{tabular}

: Fonte: Elaboração própria a partir de dados do Censo Demográfico, 2000 (IBGE). A Tabela apresenta os valores médios, totais e por quartil da distribuição da taxa de urbanização, das variáveis selecionadas nos municípios distantes até $200 \mathrm{~km}$ das rodovias (menor distância considerando a curvatura da Terra) criados após a construção de Belém-Teresina (a); e posteriormente à pavimentação da Cuiabá-Porto Velho (b). Na área de Cuiabá-Porto Velho não foram incluídos os municípios criados no Estado do Mato Grosso. As taxas e percentuais estão em escala de 0 a 1. As informações são referentes ao Censo Demográfico 2000 (IBGE). 
Com o aumento da taxa de urbanização, há um aumento da média da população total tanto na área da Belém-Teresina como da Cuiabá-Porto Velho, denotando uma correlação positiva entre urbanização e aglomeração, freqüentemente explorada na literatura sobre cidades (Fujita and Thisse (2002); Huriot and Thisse (2000)). Contudo, no caso da medida de densidade demográfica, razão entre a população total e a área total do município, apenas, na Belém-Teresina, há um aumento da média, que varia de 13,97 a 49,70, com a urbanização. Na área da Cuiabá-Porto Velho, as densidades são bem inferiores, vão de 5,60 a 7,87, sendo maior para o primeiro quarto da distribuição, isso porque, especialmente na região da Amazônia Ocidental, os municípios tendem a ser muito extensos, quando se considera a área total dos municípios, incluindo regiões de matas densas e terras não-aproveitáveis.

De outro lado, as variáveis de escolaridade apontam que, nas duas rodovias, há um aumento da média de anos de estudo nos quartos da distribuição com taxas de urbanização mais elevadas. Mais uma vez, a evidência empírica reforça o argumento de economistas urbanos que apontam para o papel da cidade como aglutinador de capital humano (Glaeser (1999); Berry and Glaeser (2005); Black and Henderson (1999)).

Simultaneamente, os municípios mais urbanizados apresentam uma maior média de percentual de trabalhadores com carteira assinada e uma redução dos não-remunerados.

A análise descritiva da urbanização na área de análise das rodovias não evidencia uma correlação clara entre aumento da taxa de urbanização e maior diversificação ou concentração de atividades. Especialmente no caso da Cuiabá-Porto Velho, a média do índice Herfindahl para atividades não-agropecuárias se mantém em torno de 0,14 em todos os quartos de distribuição, havendo uma queda pouco expressiva nos últimos quartos da distribuição. Já na área da Belém-Teresina, o aumento desse índice, quando se compara os dois primeiros quartos com os dois últimos, parece estar associado a uma maior participação do comércio no total de ocupados.

Por fim, como esperado, olhando a distribuição dos municípios por taxa de urbanização, há um incremento do percentual de residentes em domicílios atendidos por serviços de abastecimento de água, esgotamento sanitário, energia e comunicação nos quartos superiores da distribuição. Isso ocorre porque a própria definição do perímetro urbano leva em consideração a existência dessa infra-estrutura básica.

Embora os municípios criados nas áreas da Belém-Teresina e da Cuiabá-Porto Velho tenham uma estrutura produtiva e demográfica bastante semelhantes, existem algumas diferenças expressivas nas variáveis de escolaridade, rendimento e acesso a serviços públicos. Na região de Cuiabá-Porto Velho, há uma superioridade nas médias de anos de estudo (3,11 para população com 10 anos ou mais contra apenas 2,11 ), no percentual de pessoas que sabem ler e escrever ( $72 \%$ em oposição a apenas $52 \%$ para a região da Belém-Teresina), nos rendimentos familiares (R\$ 227,00 no rendimento familiar total per capita contra apenas R\$ 91,41 nos municípios da Belém-Teresina). Além disso, a cobertura de todos os serviços de infra-estrutura é maior na Cuiabá-Porto Velho.

\subsection{Resultados das estimações da relação entre urbanização e renda em cidades emergentes}

A Tabela 5 apresenta os resultados das estimações da equação de rendimento por mínimos quadrados ordinários para os residentes em municípios novos nas áreas de análise das rodovias Belém-Teresina e Cuiabá-Porto Velho. Para contornar o problema de não independência entre as observações individuais decorrente da inclusão de variáveis municipais, as estimações são realizadas considerando cluster de município como método de correção da variância. 
Table 5: Regressão OLS $L N$ Rendimento Total - Áreas da Rodovia Belém-Teresina e Cuiabá-Porto Velho

\begin{tabular}{|c|c|c|c|c|}
\hline \multirow[t]{2}{*}{ Variáveis } & \multicolumn{2}{|c|}{ (1) } & \multicolumn{2}{|c|}{ (2) } \\
\hline & Belém - Teresina & $\begin{array}{lll}\text { Cuiabá - Porto } \\
\text { Velho }\end{array}$ & Belém - Teresina & $\begin{array}{lll}\text { Cuiabá - Porto } \\
\text { Velho }\end{array}$ \\
\hline \multirow[t]{2}{*}{ Reside no Meio Urbano? } & 0,187 & $0,122^{3}$ & $-0,087^{1}$ & $-0,065^{3}$ \\
\hline & $(0,121)$ & $(0,023)$ & $(0,048)$ & $(0,018)$ \\
\hline \multirow[t]{2}{*}{ Taxa de Urbanização } & $0,655^{3}$ & 0,047 & $0,219^{1}$ & $-0,003$ \\
\hline & $(0,222)$ & $(0,097)$ & $(0,116)$ & $(0,178)$ \\
\hline Demografia - Características Individuais & & & Sim & Sim \\
\hline \multicolumn{5}{|l|}{ Indicadores Demográficos Municipais } \\
\hline \multirow[t]{2}{*}{ Logaritmo natural da População } & & & $0,094^{3}$ & $-0,02$ \\
\hline & & & $(0,022)$ & $(0,031)$ \\
\hline \multirow[t]{2}{*}{ Logaritmo Natural da Densidade } & & & $-0,048^{3}$ & 0,034 \\
\hline & & & $(0,016)$ & $(0,023)$ \\
\hline \multirow[t]{2}{*}{ \% População com 15 anos ou Mais } & & & 0,093 & $-0,59$ \\
\hline & & & $(0,172)$ & $(2,171)$ \\
\hline \multirow[t]{2}{*}{ \%População com 25 anos ou Mais } & & & $-0,574^{3}$ & $-0,413$ \\
\hline & & & $(0,156)$ & $(2,470)$ \\
\hline Migração - Características Individuais & & & Sim & Sim \\
\hline \multicolumn{5}{|l|}{ Indicador Municipal de Migração } \\
\hline \multirow[t]{2}{*}{ \% de Imigrantes na População } & & & $0,282^{1}$ & $-0,107$ \\
\hline & & & $(0,169)$ & $(0,115)$ \\
\hline Trabalho - Características Individuais & & & Sim & Sim \\
\hline \multicolumn{5}{|l|}{ Indicadores Municipais de Trabalho } \\
\hline \multirow[t]{2}{*}{ Taxa de Ocupação no Município } & & & $-0,413^{3}$ & $1,339^{3}$ \\
\hline & & & $(0,121)$ & $(0,411)$ \\
\hline \multirow[t]{2}{*}{ Proxy p/Produtividade } & & & $0,036^{3}$ & $0,033^{3}$ \\
\hline & & & $(0,007)$ & $(0,006)$ \\
\hline \multirow[t]{2}{*}{ Média de Horas Trabalhadas no Município } & & & 0,005 & 0,009 \\
\hline & & & $(0,004)$ & $(0,006)$ \\
\hline \multirow[t]{2}{*}{ \% de Ocupados na Agropecuária } & & & $0,707^{3}$ & $-0,430^{1}$ \\
\hline & & & $(0,129)$ & $(0,249)$ \\
\hline \multirow[t]{2}{*}{ Herfindahl de Atividades Econômicas } & & & 0,09 & 0,266 \\
\hline & & & $(0,196)$ & $(1,051)$ \\
\hline$\%$ Ocupados c/ carteira assinada & & & 0,196 & 0,153 \\
\hline & & & $(0,161)$ & $(0,394)$ \\
\hline Educação - Características Individuais & & & $\operatorname{Sim}$ & Sim \\
\hline Indicadores Municipais de Educação & & & & \\
\hline \% Sabe Ler e Escrever no Município & & & $-0,142$ & $-0,136$ \\
\hline & & & $(0,170)$ & $(1,028)$ \\
\hline Média de Anos de Estudo: & & & & \\
\hline População com 10 anos ou + & & & 0,039 & $-0,798$ \\
\hline & & & $(0,174)$ & $(0,510)$ \\
\hline População com 15 anos ou + & & & $-0,05$ & 0,726 \\
\hline & & & $(0,158)$ & $(0,659)$ \\
\hline População com 25 anos ou + & & & 0,04 & $-0,159$ \\
\hline & & & $(0,039)$ & $(0,406)$ \\
\hline Características de infra-estrutura domiciliar & & & Sim & $\operatorname{Sim}$ \\
\hline Indicadores Municipais de infra-estrutura & & & & \\
\hline$\%$ de pessoas em domicílio com: & & & & \\
\hline Telefone & & & $-0,115$ & 0 \\
\hline & & & $(0,412)$ & $(0,243)$ \\
\hline Iluminação Elétrica & & & $-0,208$ & $-0,246$ \\
\hline & & & $(0,130)$ & $(0,223)$ \\
\hline Água canalizada & & & $0,371^{2}$ & $-0,317^{2}$ \\
\hline & & & $(0,175)$ & $(0,133)$ \\
\hline Rede geral de esgotamento sanitário & & & 0,035 & $0,349^{2}$ \\
\hline & & & $(0,065)$ & $(0,163)$ \\
\hline Rede geral de água & & & $-0,283^{1}$ & $-0,101$ \\
\hline & & & $(0,151)$ & $(0,148)$ \\
\hline
\end{tabular}


Table 5: Regressão OLS $L N$ Rendimento Total - Áreas da Rodovia Belém-Teresina e Cuiabá-Porto Velho

\begin{tabular}{|c|c|c|c|c|}
\hline \multirow[t]{2}{*}{ Variáveis } & \multicolumn{2}{|c|}{ (1) } & \multicolumn{2}{|c|}{ (2) } \\
\hline & Belém - Teresina & $\begin{array}{lll}\text { Cuiabá - Porto } \\
\text { Velho }\end{array}$ & Belém - Teresina & $\begin{array}{lll}\text { Cuiabá - Porto } \\
\text { Velho }\end{array}$ \\
\hline \multirow[t]{2}{*}{ Constante } & $4,629^{3}$ & $5,481^{3}$ & $2,494^{3}$ & $3,283^{3}$ \\
\hline & $(0,099)$ & $(0,047)$ & $(0,355)$ & $(0,888)$ \\
\hline Total de Observações & 73902 & 29702 & 73902 & 29702 \\
\hline $\mathrm{R}^{2}$ & 0,04 & 0,00 & 0,48 & 0,33 \\
\hline \multicolumn{5}{|l|}{ Testes $F$ de Significância Conjunta } \\
\hline Urbanização & $8,140^{3}$ & $13,630^{3}$ & $2,450^{1}$ & $7,190^{3}$ \\
\hline Características Individuais - Demografia & & & $131,38^{3}$ & $443,79^{3}$ \\
\hline Indicadores Demográficos Municipais & & & $9,35^{3}$ & 1,04 \\
\hline Migração - Características Individuais & & & $3,40^{2}$ & $27,20^{3}$ \\
\hline Indicador Municipal de Migração & & & $2,78^{1}$ & 0,86 \\
\hline Características Individuais de Trabalho & & & $103,30^{3}$ & $207,63^{3}$ \\
\hline Indicadores Municipais de Trabalho & & & $14,79^{3}$ & $8,18^{3}$ \\
\hline Características Individuais de Educação & & & $36,26^{3}$ & $260,89^{3}$ \\
\hline Indicadores Municipais de Educação & & & 0,54 & 1,66 \\
\hline Características de Infra-Estrutura Domiciliar & & & $16,52^{3}$ & $59,58^{3}$ \\
\hline Indicadores Municipais de Infra-Estrutura & & & 1,77 & $5,87^{3}$ \\
\hline
\end{tabular}

A Tabela 5 apresenta as estimações por mínimos quadrados ordinários do logaritmo natural do rendimento, tendo como variáveis explicativas características individuais e do município de residência do indivíduo. Na coluna (1), foram feitas regressões, para as áreas de análise das rodovias Belém-Teresina e Cuiabá-Porto Velho, do logaritmo natural do rendimento total do indivíduo em função da dummy "reside no meio urbano" e da taxa de urbanização do município. Esse exercício foi feito considerando apenas aqueles municípios criados após as obras viárias consideradas. Da coluna (1) para a coluna (2) são incluídas variáveis agregadas e individuais relativas à demografia, estrutura produtiva e mercado de trabalho, educação e infra-estrutura de serviços públicos básicos. As taxas e percentuais variam entre 0 e 1. Entre parênteses são apresentados os desvios padrões robustos dos coeficientes. Coeficientes significativos ao nível de $10 \%$ são denotados por $\left({ }^{1}\right)$, a $5 \%$ por $\left({ }^{2}\right)$, e a $1 \%$ por $\left({ }^{3}\right)$. Em todas as regressões foram realizadas correções para o desenho amostral considerando os pesos dos indivíduos e cluster de município. A tabela traz ainda testes de significância conjunta por grupos de variáveis. No caso da área de análise da Cuiabá-Porto Velho, foram excluídos os municípios do Estado do Mato Grosso.

Em Belém-Teresina, a primeira regressão de rendimento (coluna 1), tendo como variáveis explicativas apenas as variáveis de urbanização, apontam que o fato do indivíduo residir ou não no meio urbano não tem uma correlação significativa com o rendimento individual em municípios de formação recente. Já o coeficiente da taxa de urbanização é significativo a 1\%, apontando que os residentes em municípios com uma taxa de urbanização 10 pontos percentuais mais elevada têm em média um rendimento cerca de $6,5 \%$ maior.

Na rodovia Cuiabá-Porto Velho, a regressão não condicionada do logaritmo natural do rendimento em função das variáveis de urbanização, diferentemente do que ocorre em municípios da Belém-Teresina, mostra que a correlação entre urbanização e renda é significativa apenas quando olhamos o coeficiente da dummy "reside no meio urbano". Um indivíduo que reside no meio urbano recebe, em média, $13 \%$ a mais.

Temos, portanto, dois resultados distintos: na Belém-Teresina, o prêmio de rendimento está associado à residência em municípios mais urbanizados, que tendem a ser os mais desenvolvidos e densamente povoados, com parcelas crescentes da mão-de-obra sendo absorvida pelo comércio, serviços e indústria (Tabela 4). A relação entre urbanização e renda estaria refletindo, na verdade, uma relação entre densidade e prêmio salarial. Este resultado reproduz, em parte, num contexto de cidades de pequeno porte em um país em desenvolvimento, com formação recente, a associação entre densidade urbana e 
maiores salários encontrada por Glaeser and Mare (2001), quando se comparam áreas metropolitanas densamente povoadas com demais localidades. Já o resultado da Cuiabá-Porto-Velho indica que o que importa é estar no perímetro urbano do município, ainda que tal município seja pouco urbanizado.

Entretanto, os coeficientes das variáveis de urbanização, nos dois casos analisados, podem, simplesmente estar capturando diferenças nas características individuais entre os residentes em um município e em outro, ou diferenças entre os próprios municípios.

Seguindo os referenciais teóricos apresentados na subseção 2.1, a coluna (2) da Tabela 5 mostra as estimações anteriores para as áreas das duas rodovias analisadas, acrescentando variáveis individuais e municipais relativas à demografia e migração; estrutura produtiva e mercado de trabalho; educação e infra-estrutura.

Tanto para os residentes em municípios criados após a construção da Belém-Teresina como para os residentes naqueles criados após a pavimentação da Cuiabá-Porto Velho, o coeficiente da dummy "reside no meio urbano" torna-se negativo. Embora o efeito seja mais significativo no último caso o efeito de residir no meio urbano é bem próximo um ao outro, -0,087 e -0,065, significando uma redução de cerca de, respectivamente, $8 \%$ e $6 \%$ no rendimento total do indivíduo.

Para os residentes na área de análise da Belém-Teresina, a regressão não condicionada já apontava para a não significância desse coeficiente, mas para a área de análise da Cuiabá-Porto Velho, o coeficiente passa de 0,122 significativo a $1 \%$ para $-0,065$ também significativo a $1 \%$, indicando que o efeito positivo que residir no meio urbano poderia ter sobre a renda não ocorre de forma direta e sim por outros canais.

Comportamento semelhante ocorre com a taxa de urbanização. Nesse caso, para os residentes na Cuiabá-Porto Velho, o coeficiente já havia se tornando próximo de zero e não significativo para a regressão não condicionada em características individuais e do município. Considerando a rodovia BelémTeresina, o coeficiente se reduz de 0,655 , significativo a $1 \%$, para 0,219 significativo a $10 \%$ apenas. Esse coeficiente indica que, condicionando nas características individuais e nas demais variáveis municipais, um município com uma taxa de urbanização 10 pontos percentuais superior, oferece, em média, um salário 2,19\% maior, o que é uma diferença de rendimento inferior aos prêmios salariais em torno de $10,5 \%$ e $4,5 \%$ das grandes cidades de um país desenvolvido (Glaeser and Mare, 2001).

Quais são, portanto, os canais que explicam a relação positiva entre as variáveis de urbanização e o rendimento individual em cada uma das áreas de análise das rodovias? Os testes F de significância conjunta por grupos de variáveis mostram que, nos dois casos, rejeita-se a hipótese nula de que as variáveis são conjuntamente iguais a zero para todos os grupos de características individuais. Já para os indicadores municipais encontramos alguns resultados distintos para os municípios da Belém-Teresina e da Cuiabá-Porto Velho.

Nas duas rodovias analisadas, os coeficientes das características individuais, referentes a quesitos demográficos, são significativos e apresentam o mesmo sinal, na média, o rendimento aumenta com a idade, homens recebem mais comparativamente a mulheres; brancos recebem mais do que negros e pardos; e casados, separados e viúvos apresentam rendimentos superiores ao dos solteiros. Quanto aos indicadores demográficos municipais, no caso da Cuiabá-Porto Velho, nenhum dos coeficientes das variáveis municipais é significativo, pelo teste F não rejeitamos a hipótese nula de que tais coeficientes sejam conjuntamente iguais a zero. Já para a Belém-Teresina, parece haver algum efeito sobre indicadores demográficos municipais sobre o rendimento individual. Embora haja correlações significativas, respectivamente, positiva e negativa, da população e da densidade demográfica com o rendimento individual, estas são bastante reduzidas, o que, de certa forma, contraria o argumento da escala do município como um dos canais da relação entre urbanização e renda (Glaeser (1999); Fujita et al. (1999)).

A maior correlação com o rendimento individual, dentre as variáveis demográficas, é mesmo o do percentual da população com 25 anos ou mais. Residir em um município onde o percentual da população com 25 anos ou mais seja 10 pontos percentuais maior está associado a uma redução de 5,74\% do rendimento individual. Essa relação retrata um pouco da associação entre o estágio de transição demográfica do município e rendimento individual. Conforme descrito na literatura de demografia, aumentando o nível de desenvolvimento do município, as taxas de fecundidade e mortalidade tendem a 
ser menores, com isso há um estreitamento da pirâmide etária, refletido pela elevação do percentual da população adulta (Kirk, 1996). Logo, se residir em um município com elevado percentual da população com 25 anos ou mais estiver relacionado com a residência em locais mais desenvolvidos, na área da Belém-Teresina, temos que os municípios de maior desenvolvimento oferecem menores rendimentos individuais, tal fato pode ser explicado pela concentração de mão-de-obra nesses locais, tendo em vista o mercado de trabalho regional ser ainda bastante restrito.

Para as variáveis individuais de migração, encontramos sinais de que os migrantes são positivamente selecionados nos municípios das duas rodovias como enfatizado na literatura de migração por autores como Borjas (1987); Borjas et al. (1992) e Chiswick (1999). Quanto ao indicador municipal de migração, existe uma correlação entre o percentual da população migrante e o rendimento individual somente para os residentes nos municípios da Belém-Teresina, mas tal relação apresenta um nível de significância de apenas $10 \%$.

Nos dois casos estudados, as variáveis de estrutura produtiva e mercado de trabalho parecem estar fortemente relacionadas ao rendimento, o que pode explicar uma parcela da correlação positiva entre variáveis de urbanização e rendimento encontrada nas regressões não condicionadas.

Na rodovia Belém-Teresina, há uma correlação negativa entre a taxa de ocupação e o rendimento. Os indivíduos que moram em um município com uma taxa de ocupação 10 pontos percentuais maior possuem, em média, um rendimento $4,1 \%$ menor. Uma explicação para essa relação pode estar associada à própria estrutura precária dessas economias, de subsistência, com relações de trabalho não-mercantis. Assim, o desemprego tende a ser menor em municípios onde o mercado de trabalho é menos desenvolvido e grande parte das pessoas são consideradas ocupadas, mas são pequenos agricultores, que trabalham como conta-própria ou como membros não-remunerados da família ou são empregados sem carteira assinada, apresentando baixos rendimentos. 0 percentual médio de trabalhadores ditos contaprópria é de $38 \%$ contra apenas $6 \%$ de trabalhadores com carteira assinada (Tabela 4).

Nos municípios da Cuiabá-Porto Velho a correlação entre a taxa de ocupação e o rendimento total do indivíduo é positiva e significativa. Residir em um município com uma taxa de ocupação 10 pontos percentuais mais elevada está associado a rendimentos $13,4 \%$ superiores. Comparativamente à área de análise da Belém-Teresina, nessa região, embora o percentual de ocupados como conta-própria seja também bastante elevado, há uma maior estruturação do mercado de trabalho local refletido numa formalização maior, com o percentual médio de $12 \%$ de trabalhadores com carteira assinada (Tabela 4).

Quanto ao coeficiente da proxy de produtividade, os resultados encontrados para as duas rodovias são praticamente os mesmos: 0,036, na Belém-Teresina e; 0,033 na Cuiabá-Porto Velho. Residir em um município em que a produtividade é maior em R\$ 1 por hora está associado a um aumento médio de 3\% no rendimento individual, o que confirma a produtividade do trabalho como um dos canais da relação positiva entre urbanização e renda (Berry and Glaeser (2005); Glaeser and Saiz (2003)).

Ainda no que se refere à estrutura produtiva, são encontrados efeitos significativos do percentual de ocupados na agropecuária sobre o rendimento individual. No caso da Belém-Teresina, o efeito é positivo e significativo a $1 \%$. Os indivíduos que moram em municípios com um percentual de ocupados na agropecuária 10 pontos percentuais superior possuem, em média, rendimentos $7 \%$ mais elevados. Cabe aqui a ressalva que estamos tratando de uma região em estágio inicial de urbanização em que a agropecuária ainda é responsável pela maior parte da absorção da mão-de-obra, de forma que a cidade surge e funciona em torno de ou em apoio a essa atividade (Tabela 4). Mesmo considerando apenas os residentes no meio urbano, a agropecuária ainda é o setor que mais emprega ( $22,3 \%$ dos ocupados).

Já na área de análise da Cuiabá-Porto Velho, a relação entre o percentual de ocupados na agropecuária e o rendimento individual é negativa, embora pouco significativa. Uma possível explicação para essa diferença de resultados entre as duas regiões pode estar na própria distribuição de ocupados por setores de atividade. Entre os que residem no meio urbano, nessa região, o maior percentual de ocupados está no comércio $(19,44 \%$ contra $15,52 \%$ na agropecuária) que remunera, em média, melhor do que a agropecuária (R\$ 735,38 em contraposição a R\$ 357,73, considerando apenas os residentes no meio urbano). 
No grupo de variáveis de educação, nas duas rodovias, apenas os anos de estudo do indivíduo têm correlação com o rendimento do indivíduo. Nos aglomerados localizados ao longo dessas rodovias, contrariamente ao que é enfatizado por diversos resultados empíricos, como o de Rauch (1993) e Chomitz et al. (2005), residir em um município em que as pessoas têm um nível mais elevado de escolaridade parece não ter efeito sobre os rendimentos individuais. Talvez, seja mais difícil a ocorrência de spillovers de conhecimento em locais com níveis muito baixo de escolaridade e elevado percentual de trabalhadores com menos de 1 ano de estudo, como ocorre em grande parte do Norte e Nordeste.

Como o efeito da urbanização é, muitas vezes, associado à infra-estrutura social básica oferecida pelas cidades, a inclusão de variáveis de infra-estrutura visa investigar a existência de alguma relação entre o rendimento individual e o acesso a serviços públicos básicos, como também, com o fato de residir em um município onde uma maior proporção de pessoas têm acesso a esses serviços. São duas as hipóteses relacionadas à infra-estrutura. De um lado, tais serviços podem ter impacto sobre a produtividade individual e coletiva, uma vez que a maior disponibilidade de tais serviços, libera parte do tempo gasto em tarefas domésticas não mais necessárias, seja pela existência da água canalizada, seja pelos benefícios da luz elétrica e comunicação mais ágil, tornando possível a maior especialização do trabalho (Fafchamps and Shilpi, 2005). Por outro lado, condições de infra-estrutura deficientes atuam como uma restrição à industrialização, relacionada à maior diversificação produtiva local (Bjorvtan, 2000).

Os resultados do teste $\mathrm{F}$ de significância conjunta de variáveis individuais referentes à infra-estrutura domiciliar apontam a existência de uma correlação significativa entre acesso individual a serviços públicos básicos e rendimento individual nos dois casos analisados.

Por fim, parece haver também uma correlação positiva entre residir em municípios onde o acesso à infra-estrutura básica é mais amplo e o rendimento individual, especialmente na área da Cuiabá-Porto Velho. Para os residentes na Belém-Teresina, embora apareça uma correlação positiva e significativa do rendimento individual com o percentual de pessoas em domicílios com água canalizada, no teste F de significância conjunta do grupo de indicadores municipais de infra-estrutura, não conseguimos rejeitar a hipótese de que seus coeficientes sejam conjuntamente iguais a zero. Na Cuiabá-Porto Velho, onde os tais variáveis são conjuntamente significativas, a maior explicação se dá via percentual de pessoas em domicílios com rede geral de esgotamento sanitário. Isso pode ser explicado pela distribuição desses indicadores municipais por quartil de urbanização (Tabela 4). Nos municípios da Cuiabá-Porto Velho não há uma relação direta entre o aumento da urbanização e aumento do percentual de pessoas em domicílios com água canalizada, enquanto que no primeiro quarto da distribuição o percentual de atendidos chega a $60 \%$, no quarto seguinte, a média é de apenas $40 \%$.

\section{CONSIDERAÇÕES FINAIS}

A relação entre urbanização e desenvolvimento, com ênfase na correlação entre urbanização e renda per capita há muito vem sendo explorada pelos teóricos de desenvolvimento econômico e economistas urbanos. Contudo, existem ainda uma série de questões que permanecem em aberto que vão desde 0 porquê das cidades se formarem até o entendimento dos canais pelos quais a urbanização se relaciona com o crescimento econômico.

O presente trabalho resgata algumas dessas questões propondo um exercício empírico para tratar a relação entre renda e variáveis de urbanização, especificamente, o status de residência no meio rural e a taxa de urbanização. Para tanto, parte da formação de cidades ocasionada pela construção/pavimentação de eixos rodoviários e, diferentemente do enfoque de grande parte literatura urbana, analisa o a relação entre rendimento individual e urbanização em cidades de pequeno porte, que nada mais são do que pequenos aglomerados populacionais em áreas de ocupação relativamente recente.

Os resultados encontrados indicam que, embora exista uma correlação positiva entre urbanização e rendimento individual, seja pelo fato do indivíduo residir no meio urbano, seja por morar em um 
município com maior percentual da população urbana, essa relação não corre de modo direto e, sim, via outros canais explorados neste artigo.

Ao contrário do enfoque central de grande parte da literatura (Berry and Glaeser (2005); Glaeser (1999); Rauch (1993)), não encontramos evidências de que exista um efeito positivo sobre o rendimento individual de se residir em um município em que a média de anos de estudo das pessoas é mais elevada, o que, de certo modo, configuraria a ocorrência de algum tipo spillovers de conhecimento, denotando a importância de se aglomerar capital humano. Uma possível explicação para esta discrepância dos resultados em relação à literatura deve-se ao contexto econômico de realização desse experimento, baseado em pequenas cidades recém-criadas em áreas de fronteira de um país em desenvolvimento, cuja organização da economia local ainda encontra-se em um estágio essencialmente de retornos constantes de escala, ou seja, de uma economia de mercado embrionária com forte nível de informalidade das relações de trabalho e níveis baixos de produtividade.

Por outro lado, nos dois casos analisados, o papel das cidades parece mesmo associado às características de seus trabalhadores e à estrutura produtiva. O fato de se encontrar uma relação positiva e significativa entre percentual de ocupados na agropecuária e rendimento individual, no caso da Belém-Teresina, abre espaço para uma discussão sobre que cidades são estas que se formam ao longo de rodovias e permanecem tendo na agropecuária o principal setor de absorção de mão-de-obra.

De forma mais geral, em ambos os casos, o processo de urbanização ocorre desvinculado de qualquer tipo de industrialização. Na verdade, a cidade parece apenas significar o surgimento de algum tipo de atividade comercial rudimentar ainda acoplada à estrutura agrária.

\section{BIBLIOGRAPHY}

Acemoglu, D., Johnson, S., \& Robinson, J. (2002). Reversal of fortune: Geography and institution in the making of the modern world income distribution. The Quarterly Journal of Economics, 117(4):12311294.

Bairoch, P. (1988). Cities and Economic Development: From the Down of History to the Present. University of Chicago.

Bank, W. (1999). Projeto úmidas: Um enfoque participatório para o desenvolvimento sustentável: 0 caso de rondônia. Technical report, World Bank (Brazil Country Management Unit. Latin America and the Caribbean Region), Washington.

Berry, C. \& Glaeser, E. (2005). The divergence of human capital level across cities. Discussion Paper 2091 Harvard Institute of Economic Research.

Bjorvtan, K. (2000). Urban infrastructure and industrialization. Journal of Urban Economics, 48(2):205218.

Black, D. \& Henderson, V. (1999). A theory of urban growth. The Journal of Political Economy, 107(2):252284.

Borjas, G. J. (1987). Self-selection and the earnings of immigrants. The American Economic Review, 77(4):531-553.

Borjas, G. J., Bronars, S. G., \& Trejo, S. J. (1992). Self-selection and internal migration in the united states. Journal of Urban Economics, 32(2):159-185.

Buarque, S. C., Lopes, A. D., \& Rosa, T. (1995). Integração Fragmentada e Crescimento Da Fronteira Norte, pages 93-123. FUNDAP- Universidade Estadual Paulista. 
Castro, N. (1984). Substituição entre modo de transporte e armazenagem e suas implicações. Revista Brasileira de Armazenamento, 12(1).

Castro, N. (1988). Estrutura e desempenho do setor de transporte rodoviário de carga. Pesquisa e Planejamento Econômico, 18(1):55-82.

Castro, N. (2002). Transportation costs and brazilian agricultural production: 1970-1996. mimeo.

Castro, N., Carry, L., \& Rodrigues, B. (1999). Custos de transporte e a estrutura espacial do comércio interestadual brasileiro. Pesquisa e Planejamento Econômico, 29(3):347-400.

Chein, F., Lemos, M. B., \& Assunção, J. J. (2007). Desenvolvimento desigual: Evidências para o brasil. Revista Brasileira de Economia, 61(3):301-330.

Chiswick, B. (1999). Are immigrants favorably self-selected? American Economic Review, 89(2):181-185.

Chomitz, K., Da Mata, D., Carvalho, A., \& Magalhães, J. (2005). Spatial dynamics of labor market in brazil. Research Working Paper 3752, World Bank.

Christaller, W. (1966). Central Places in Southern Germany. Prentice-Hall, New Jersey.

Da Mata, D., Deichmann, U., Henderson, J. V., Lall, S. V., \& Wang, H. (2005a). Determinants of city growth in brazil. Working Paper 11585, National Bureau of Economic Research.

Da Mata, D., Deichmann, U., Henderson, J. V., Lall, S. V., \& Wang, H. G. (2005b). Examining the growth patterns of Brazilian cities. Policy Research Working Paper Series 3724, The World Bank.

Da Mata, D., Deichmann, U., Henderson, J. V., Lall, S. V., \& Wang, H. G. (2006). Um exame dos padrões de crescimento das cidades brasileiras. Technical Report 1155, Instituto de Pesquisa Econômica Aplicada - IPEA. http://ideas.repec.org/p/ipe/ipetds/1155.html.

Diniz, C. C. (1987). Capitalismo, Recursos Naturais e Espaço. PhD thesis, Unicamp.

Fafchamps, M. \& Shilpi, F. (2005). Cities and specialisation: Evidence from south asia. Economic Journal, 115(503):477-504.

Fearnside, P. M. (1987). Deforestation and international economic development projects in brazilian amazonia. Conservation Biology, 1(3):1523-1739.

Fujita, M., Krugman, P., \& Venables, A. (1999). The Spatial Economy: Cities, Regions and International Trade. MIT, Cambridge, Mass. 367p.

Fujita, M. \& Thisse, J.-F. (2002). Economics of Agglomeration: Cities, Industrial Location and Regional Growth. Cambridge University, Cambridge, Mass. 480p.

Gallup, J., Sachs, J., \& Mellinger, A. (1998). Geography and economic growth. In Annual World Bank Conference on Development Economics, pages 127-178, Washington, D.C. Pleskovic, B. and Stiglitz, J.E., World Bank.

Glaeser, E. L. (1999). Learning in cities. Journal of Urban Economics, 46(2):254-277.

Glaeser, E. L., Kallal, H. D., Scheinkman, J. A., \& Shleifer, A. (1992). Growth in cities. Journal of Political Economy, 100(6):1126-52.

Glaeser, E. L. \& Kohlhase, J. E. (2003). Cities, regions and the decline of transport costs. Working Paper 9886, National Bureau of Economic Research. 
Glaeser, E. L. \& Mare, D. C. (2001). Cities and skills. Journal of Labor Economics, 19(2):316-42.

Glaeser, E. L. \& Saiz, A. (2003). The rise of the skilled city. Harvard Institute of Economic Research Working Papers 2025, Harvard - Institute of Economic Research.

Glaeser, E. L., Scheinkman, J. A., \& Shleifer, A. (1995). Economic growth in a cross-section of cities. Working Paper 5013, National Bureau of Economic Research.

Greenwood, M. J. (1975). Research on internal migration in the united states: A survey. Journal of Economic Literature, 13(2):397-433.

Henderson, J. (1999). Overcoming the adverse effects of geography: Infrastructure, health, and agricultural policies. International Regional Science Review, 22(2):233-237.

Henderson, J. V. (1974). The sizes and types of cities. The American Economic Review, 64(4):640-656.

Henderson, J. V. \& Wang, H. G. (2005). Aspects of the rural-urban transformation of countries. Journal of Economic Geography, 5(1):23-42.

Hoselitz, B. F. (1953). The role of cities in the economic growth of underdeveloped countries. Journal of Political Economy, 61:195.

Huriot, J.-M. \& Thisse, J.-F. (2000). Economics of Cities: Theoretical Perspectives. Cambridge University, Cambridge, Mass.

IBAM (2006). Evolução do município brasileiro. Acesso em 04/09/2006. http://www . ibam.org. br/ municipio/criacao.htm.

Isard, W. \& Bramhall, D. (1960). Methods of Regional Analysis: An Introduction to Regional Science. MIT, Cambridge, Mass.

Jacobs, J. (1969). The Economy of Cities. Penguin Books.

Kirk, D. (1996). Demographic transition theory. Population Studies, 50(3):361-87.

Kuznets, S. (1966). Modern Economic Growth: Rate Structure and Spread. Yale University, New Haven.

Lewis, A. (1954). Economic development with unlimited supplies of labor. Manchester School of Economic Social Studies, 22:139-191.

Lösh, A. (1954). The Economics of Location. Yale University, New Haven.

Margulis, S. (1991). O desempenho do governo brasileiro, dos órgãos contratantes e do banco mundial em relação à questão ambiental do programa polonoroeste. Technical Report 227, Instituto de Pesquisa Econômica Aplicada, Rio de Janeiro.

Martine, G. (1995). A Evolução Espacial Da População Brasileira, pages 61-91. FUNDAP-Universidade Estadual Paulista, São Paulo.

Pred, A. R. (1966). The Spatial Dynamics of U.S. Urban-Industrial Growth, 1800-1914: Interpretative and Theoretical Essays. MIT, Cambridge Mass.

Rauch, J. E. (1993). Productivity gains from geographic concentration of human capital: Evidence from the cities. Journal of Urban Economics, 34(3):380-400.

Rondônia-SEPLAG (2002). Diagnóstico sócio-econômico do estado de rondônia. Technical report, Secrataria do Estado do Planejamento, Coordenação Geral e Administração. Acesso em 06/02/2006. 


\section{A. TABELAS}

Table A-1: Grupos de Atividades, Categorias Ocupacionais e Posição na Ocupação

\begin{tabular}{|l|l|l|}
\hline Grupos de Atividades & Grupos de Categorias Ocupacionais & Posição na Ocupação \\
\hline Atividades Agropecuárias & Ocupações Administrativas & Empregado com Carteira Assinada \\
Extração & Ocupações técnicas, científicas, artísticas e assemelhadas & Empregado sem Carteira Assinada \\
Indústria Moderna & Ocupações da agropecuária e da produção extrativa vegetal e animal & Empregador \\
Indústria Tradicional & Ocupações da produção extrativa mineral & Conta-Própria \\
Construção Civil & Ocupações das indústrias de transformação e construção civil & Não-Remunerado \\
Serviços Públicos & Ocupações do comércio e atividades auxiliares & \\
Serviços Pessoais & Ocupações dos transportes e comunicações & \\
Serviços Produtivos & Ocupações da prestação de serviços & \\
Serviços Distributivos & Ocupações da defesa nacional e segurança pública & \\
Serviços de Ensino e Saúde & Outras ocupações, ocupações mal definidas ou não declaradas & \\
Serviços Institucionais & & \\
Comércio & & \\
Outras Atividades & & \\
\hline
\end{tabular}

: Fonte: Elaboração própria. 